\title{
TRIBUNALES ESPAÑOLES Y DERECHO INTERNACIONAL PRIVADO: EL ASUNTO CENTRAL SANTA LUCÍA CONTRA MELIÁ HOTELES. HISTORIA DE UN DESENCUENTRO PALMARIO...(CONTINUARÁ)
}

\author{
SPANISH COURTS AND PRIVATE INTERNATIONAL LAW: \\ CENTRAL SANTA LUCÍA V. MELIÁ HOTELES CASE. HISTORY \\ OF AN OBVIOUS DISAGREEMENT... (TO BE CONTINUED)
}

\author{
Aurora Hernández RodríGuez \\ Profesora Titular de Derecho Internacional Privado \\ Universidad de Cantabria \\ ORCID ID: 0000-0002-1376-497X
}

Recibido: 15.12.2020 / Aceptado: 14.01.2020

DOI: https://doi.org/10.20318/cdt.2021.5962

\begin{abstract}
Resumen: En abril de 2019, la Administración Trump activó el Título III de la Ley Helms-Bruton, provocando con ello un gran revuelo en la comunidad internacional. Para defenderse de los efectos extraterritoriales de una medida de tal envergadura, los Estados que mantienen relaciones comerciales con Cuba han elaborado "normas antídoto", cuyo principal objetivo es neutralizar los perjuicios económicos que pudieran derivarse de las potenciales demandas presentadas ante los Tribunales estadounidenses por parte de ciudadanos de aquel país en reclamación de una compensación por el acto de nacionalización llevado a cabo por el Estado de Cuba en el año 1959. En este contexto de litigación internacional instaurado por normas unilaterales de diferentes Estados, Central Santa Lucía, una empresa estadounidense, interpone ante los Tribunales españoles una acción por enriquecimiento injustificado contra Meliá Hoteles, empresa con domicilio en España, iniciándose con ello un verdadero "viacrucis judicial" en torno a cuestiones esenciales de Derecho internacional privado.

Palabras clave: Ley Helms-Burton, Estatuto de Bloqueo UE, Nacionalizaciones, Enriquecimiento injustificado, Jurisdicción, Competencia judicial internacional, Conexidad, Litisconsorcio Pasivo Necesario, Derecho aplicable, Eficacia extraterritorial, Actos de Estado.
\end{abstract}

Abstract: In April 2019, the Trump Administration activated Title III of the Helms-Bruton Act, causing a stir in the International Community. To defend themselves against the extraterritorial effects of a measure of such magnitude, the States that maintain commercial relations with Cuba have developed "antidote norms", the main objective of which is to neutralize the economic damages that could derive from the potential lawsuits presented before the United States Courts by citizens of that country in claim of compensation for the act of nationalization carried out by the State of Cuba in 1959. In this context of international litigation established by unilateral norms of different States, Central Santa Lucía, a United States company, files an action for unjustified enrichment before the Spanish Courts against Meliá Hoteles, a company domiciled in Spain, thus initiating a true "judicial viacrucis" regarding essential questions of Private International Law.

Keywords: Helms-Burton Act, EU Blocking Statute, Nationalizations, Unjust Enrichment, Jurisdiction, Multiple defendants, Act of State, Applicable Law, Extraterritorial effectiveness. 
Sumario: I. Introducción. II. Título III de la Ley Helms-Burton. III. Efectos colaterales de la Ley Helms-Burton en España. 1. Asunto Central Santa Lucía contra Meliá Hoteles: Hechos y cuestiones jurídicas planteadas. 2. Auto JPI de Palma de Mallorca, de 2 de octubre de 2019 y Auto AP de Palma de Mallorca, de 18 de marzo de 2020. 3. Auto JPI de Palama de Mallorca, de 6 de julio de 2020 y Auto JPI de Palma de Mallorca, de 30 de noviembre de 2020. The NeverEnding Story... IV. Algunas consideraciones en torno al asunto Central Santa Lucía contra Meliá Hoteles.1. Inmunidad de jurisdicción versus eficacia internacional de las nacionalizaciones. 2. Competencia judicial internacional. A) Enriquecimiento injustificado. B) Litisconsorcio pasivo necesario. 3. Cuestiones de Derecho aplicable. V. Eficacia internacional de las nacionalizaciones. 1. Consideraciones previas. 2. Perspectiva de Derecho Internacional Privado. A) Competencia internacional del Estado que ordena el acto de nacionalización. B) Conformidad con el orden público internacional. VI. Conclusiones.

\section{Introducción}

1. El Derecho Internacional Privado es una rama del ordenamiento jurídico que, en algunas ocasiones, demasiadas tal vez, recibe un tratamiento inapropiado por parte de los Tribunales españoles. Resulta cuando menos curioso y en cierta medida contradictorio, si se tiene en cuenta el importante papel que la jurisprudencia está llamada a desempeñar en el desarrollo de esta disciplina ${ }^{1}$.

2. La complejidad de las situaciones privadas internacionales y de las normas que la regulan no debiera servir de excusa a una incorrecta aplicación de las mismas. Cierto es que a veces, la realidad global en la que vivimos supera a cualquier tipo de ficción jurídica, haciendo surgir litigios que ponen a prueba la pericia de todo operador jurídico. El asunto Central Santa Lucía contra Meliá Hoteles es, sin lugar a dudas, un claro ejemplo de ello².

3. Para poder afrontar en sus debidos términos jurídicos el mencionado asunto, así como las diversas resoluciones que está generando el mismo ante los Tribunales españoles, resulta más que necesario comenzar contextualizando el escenario internacional del cual deriva: el Título III de la Ley Helms-Burton, para posteriormente pasar a analizar lo que podríamos calificar ya, como un verdadero "viacrucis judicial" de Derecho internacional privado.

\section{EI Título III de la Ley Helms-Burton}

4. En abril de 2019 la Administración de Donal Trump decidió activar el Título III de la Cuban Liberty and Democratic Solidarity (Libertad) Act de 199633, más conocida como Ley Helms-Burton 4

\footnotetext{
${ }^{1}$ Vid. A. -L. Calvo Caravaca/J. Carrascosa GonZÁlez, Derecho Internacional Privado, Vol. I, $18^{\text {a }}$ ed., Granada, Comares, 2018, pp. 92 y 93.

${ }^{2}$ El presente trabajo es una versión ampliada de la comunicación presentada bajo el título "Efectos colaterales de la Ley Helms-Burton en España. Reflexiones en torno al asunto Central Santa Lucía contra Meliá Hoteles" en el V Seminario AEPDIRI sobre Temas de actualidad de Derecho Internacional Privado, "Nuevos Escenarios del Derecho Internacional Privado de la Contratación", celebrado en la Universidad de Oviedo, el 24 de septiembre de 2020.

${ }^{3}$ Texto de la ley disponible en: https://www.congress.gov/bill/104th-congress/house-bill/927. Puede consultarse una versión en castellano: https://web.archive.org/web/20061019012534/http://www.icap.cu/pdf/ley\%20helms\%20burton.pdf.

${ }^{4}$ Sobre la Ley Helms-Burton, vid.: F. J. Garcimartín ALFÉrez, "El coste de la Ley Helms-Burton para las empresas españolas", Derecho de los Negocios, 1996, núm. 72, pp. 13-27; J. L. IRIARTE Ángel, "La Ley Helms-Burton y la respuesta europea a sus efectos extraterritoriales", Cuadernos Europeos de Deusto, 2010, núm. 63, pp. 81-112; C. LÓPEZ JURADO, "La controversia entre la Unión europea y Estados Unidos relativa a la Ley Helms-Burton", RDCE, 1997, núm. 2, pp. 581-595; A. F. LOWENFELD, "The Cuban Liberty and Democratic Solidarity (Libertad) Act: Congress and Cuba. The Helms Burton-Act", AJIL, 1996, pp. 419-434; C. OTERO GARCÍA-CASTRILLÓN, "La Ley de Libertad y Solidaridad Democrática con Cuba (Libertad Act) en el marco de la regulación del comercio internacional", REDI, 1997, núm. 1, pp. 372-377; J. RoY, "La Ley Helms-Burton: Desarrollo y consecuencias", $R D C E$, 1997, núm. 2, pp. 487-510; CH. R. SEPPALA, "La pratique américain récente: les lois Helms-Burton et d'Amato-Kennedy", en AAvv, Sanctions unilaterales, mondialisation du commerce et ordre juridique international. À propos des lois Helms-Burton et d'Amato-Kennedy, París, Montchrestein, 1998, pp. 83-97
} 
provocando con ello un gran revuelo en la comunidad internacional ${ }^{5}$. El Título III de la mencionada ley, que entró en vigor el 2 de mayo de 2019, reconoce un derecho subjetivo a los ciudadanos estadounidenses frente a todas aquellas empresas nacionales o extranjeras que "trafiquen" con propiedades o bienes nacionalizados desde el 1 de enero de 1959 por el Estado cubano sin haber mediado compensación ${ }^{6}$.

5. La Ley Helms-Burton crea, en definitiva, una tasa a las inversiones extranjeras en Cuba y con ello un obstáculo impuesto unilateralmente al libre comercio mundial ${ }^{7}$. Para neutralizar los efectos perversos que una medida de tal envergadura pudiera acarrear en el tráfico comercial internacional, algunos países han recurrido a "normas de bloqueo" o "normas antídoto". Este tipo de normas, cuyo principal objetivo es protegerse frente a la extraterritorialidad de la Ley Helms-Burton contemplan entre otras la adopción

${ }^{5}$ La Cuban Liberty and Democratic Solidarity (Libertad) Act de 1996, más conocida como Ley Helms-Burton, apellidos de sus patrocinadores republicanos, fue promulgada el 12 de marzo de 1996. Dicha ley viene a completar el embargo decretado por EEUU a Cuba a través de la Cuban Democracy Act de 1992 o "Ley Torricelli", mediante los siguientes mecanismos: a) Prohibición de préstamos, créditos o financiación por parte de ciudadanos o residentes de los EEUU en transacciones de propiedades confiscadas (Sección 103); b) Obligación del Gobierno de EEUU de votar contra la admisión de Cuba en ciertas instituciones internacionales como el FMI o el BM, hasta que no resurja la democracia en Cuba (sección 104); c) Reconocimiento de un derecho a los ciudadanos de EEUU a demandar ante los tribunales federales a compañías extranjeras que "trafiquen" con propiedades confiscadas por Cuba y extiende ese derecho a las personas que no eran ciudadanos estadounidenses en el momento de dicha confiscación, en su mayoría cubanos (Título III), d) Denegación del visado de entrada a los EEUU de extranjeros, -directivos de empresas y sus familiares-, que hayan traficado con bienes confiscados (Título IV). Los aspectos más polémicos aparecen regulados en sus títulos III y IV. Concretamente, el título III ofrece a los ciudadanos estadounidenses que sufrieron la expropiación de sus propiedades en Cuba, sin mediar compensación económica alguna, un mecanismo efectivo para resarcirse por tales hechos acaecidos tras la revolución de 1959. No obstante, el principal objetivo del título III de la Ley Helms-Burton es más bien disuadir la inversión extranjera en Cuba dinamitando con ello las medidas de liberalización económica, adoptadas por el Gobierno cubano tras el colapso de sus relaciones económicas con la extinta Unión Soviética. De tal manera, los EEUU pretenden imponer a terceros países su embargo sobre Cuba, forzando con ello su política exterior. De ahí que, desde el momento de su promulgación, la Ley Helms-Burton creara serios enfrentamientos entre los EEUU y sus aliados políticos y comerciales, entre ellos sus socios en el Tratado de Libre Comercio y la Unión Europea (por aquel entonces, Comunidad Europea). Concretamente, la UE solicitó, el 15 de julio de 1996, al Presidente Clinton que renunciase a la aplicación del Título III de la Ley, quien procedió el 17 de julio de 1996 a la suspensión del mencionado Título por un periodo de seis meses. La propia Ley Helms-Burton contempla la posibilidad de prórroga. Aun así, dicha medida fue considerada insuficiente por la UE, dando lugar, por un lado, a la presentación de una demanda ante la OMC, y por otro lado, a la elaboración de un arsenal de medidas tendentes a neutralizar los efectos extraterritoriales de la Ley Helms-Burton. Meses más tarde, el 11 de abril de 1997, la Comisión Europea y los EEUU llegan a un principio de acuerdo en cuya virtud, la UE se compromete a retirar la demanda ante la OMC, y los EEUU por su parte, a suspender indefinidamente el Título III, así como "dulcificar" la aplicación del Título IV.

${ }^{6}$ Para una mayor precisión del supuesto normativo contemplado en el Título III de la Ley Helms-Burton (Secciones 301306) resulta necesario destacar los siguientes aspectos: a) la norma afecta a cualquier persona, natural o jurídica (Secc. 4 apartado 11). Para determinar la nacionalidad de una persona jurídica la Ley Helms-Burton sigue la tesis de la constitución (Secc. 4 apartado 8, B); b) El término "traficar", abarca cualquier actividad comercial que utilice o se beneficie de propiedades confiscadas, así como que provoque, participe o se beneficie del tráfico que realicen otras personas o realizarlo a través de otros (Sección 4 apartado 13). Quien trafica ha de ser consciente de que trafica con propiedades confiscadas (Sección 4, apartado 9). Si se dispone de autorización del titular estadounidense, el tráfico se considera lícito (Sección 13 apartado A); c) Por "propiedades confiscadas" se entienden aquellas que hayan sido confiscadas por el Estado cubano desde el 1 de enero de 1959 sin satisfacer una adecuada indemnización o sin que le perjudicado hubiese llegado a un acuerdo al respecto (Sección 4, apartado 4); d) Para probar que se tiene derecho sobre una propiedad confiscada, esta ha de tener un valor superior a $50.000 \$$, y ha de aportarse un certificado emitido por la Foreign Claims Settlement Commisssion, y si no lo hubiere, cabe solicitar un dictamen pericial a tal efecto al citado organismo (Sección 302 y 303); e) el derecho a reclamar ante tribunales federales solo se atribuye a nacionales estadounidenses, no siendo necesario que tuviesen dicha nacionalidad en el momento de la confiscación (Sección 303, apartado b). Este derecho que reconoce la Ley Helms-Burton puede suspenderse (Sección 204, apartado a y Sección 306) o extinguirse una vez se implante un régimen democrático en Cuba (Secciones 201-2016 y sección 302, aparatado h), y está sujeto a un plazo de prescripción de dos años desde que se realizó el tráfico (Sección 305); i) Dicho plazo comenzará a contar desde la entrada en vigor del Título III de la Ley Helms-Burton, esto es, desde el 2 de mayo de 2019 (Sección 301, apartado a y Sección 305, apartado a); j) Si se dan todas las condiciones descritas, se podrá reclamar el pago de una determinada cantidad. La cuantía de la sanción económica no tiene carácter compensatorio, sino punitivo. Esta es independiente de los beneficios que esté obteniendo la empresa que "trafica" con la propiedad confiscada. Y finalmente, el recurso a esta reclamación excluye cualquier otro remedido que traiga la misma causa (Sección 302). Vid. F. J. GARCIMARTín ALFÉREZ, loc. cit., nota 1, pp. 14-18; J. L. IRIARTE ÁNGEL, loc. cit., nota 1, p. 84-89.

${ }^{7}$ Vid. F. J. Garcimartín AlFÉrez, loc. cit., nota 1, p. 13.

${ }^{8} \mathrm{Vid}$. H. Altozano GaRcía-FIGUERAS, La protección de las inversiones españolas en el exterior, Madrid, Instituto Español de Comercio Exterior, 2001, pp. 114-118. 
de las siguientes medidas: a) exclusión de la cooperación judicial con los tribunales norteamericanos en los asuntos derivados de la Ley Helms-Burton; b) imposición de sanciones a las empresas nacionales que acaten la mencionada ley; c) reconocimiento a las empresas nacionales afectadas por la Ley Helms-Burton del derecho a recuperar en su país los importes pagados al que fuera demandante en EE.UU .

6. La UE dispone de su propio estatuto de bloqueo o "blocking statute", recogido esencialmente en el Reglamento (CE) núm. 2271/96 del Consejo, de 22 de noviembre de 1996, relativo a la protección contra los efectos de la aplicación extraterritorial de la legislación adoptada por un tercer país, y contra las acciones basadas en ella o derivadas de ella (en adelante, estatuto de bloqueo UE) ${ }^{10}$. Dicho Reglamento ha sido actualizado y desarrollado a través de dos instrumentos ${ }^{11}$ : el Reglamento Delegado (UE) 2018/1100 de la Comisión, de 6 de junio de $2018^{12}$ y el Reglamento de Ejecución (UE) 2018/1101 de la Comisión, de 3 de agosto de $2018^{13}$. Este último Reglamento se complementa con las disposiciones adoptadas a tal efecto por los Estados miembros ${ }^{14}$.

7. Desde un punto de vista jurídico-privado, el estatuto de bloqueo UE prevé las siguientes medidas en caso de reclamaciones o inicio de acciones en EE.UU en aplicación de la Ley Helms-Burton: a) Denegación del reconocimiento y ejecución de resoluciones judiciales o administrativas extranjeras que hagan efectiva la Ley Helms-Burton (art. 4); b) Prohibición de atender requerimientos de juzgados extranjeros que se encuentren tramitando acciones basadas o derivadas de la mencionada ley (art. 5); y c) Derecho a obtener una compensación por cualquier daño, incluidas las costas procesales, causado por la aplicación de la Ley Helms-Burton . En este último caso, los afectados podrán interponer demanda ante los tribunales de cualquier Estado miembro en el que la persona física o jurídica, o cualquier otra entidad, que haya causado el daño, o cualquier persona que actúe en su nombre o como intermediario, posea activos. Se amplían así, los foros de competencia judicial internacional previstos en el Reglamento (UE) núm. 1215/2012 del Parlamento Europeo y del Consejo, de 22 de diciembre de 2012, relativo a la competencia, el reconocimiento y la ejecución de resoluciones judiciales en materia civil y mercantil (art. 6) ${ }^{15}$.

8. En este escenario, construido sobre la base de normas unilaterales (Ley Helms-Burton versus Estatuto de bloqueo UE), se crea la atmósfera perfecta para el surgimiento de una auténtica "guerra transoceánica de Derecho Internacional Privado"16. Desde el punto de vista de la litigación internacional, los nacionales estadounidenses beneficiados por el Título III de la Ley Helms-Burton tendrían las siguientes posibilidades: a) demandar ante los tribunales estadounidenses, teniendo en cuenta que el éxito de su reclamación se verá determinado por los activos que posea en aquel Estado el demandado extranjero (téngase en cuenta la imposibilidad de ejecutar la sentencia en territorio UE: estatuto de bloqueo); b) demandar ante los tribunales del país donde tenga su domicilio/activos la empresa extranjera que "trafica" con bienes "confiscados". Si bien, las posibilidades de éxito de esta última opción serían más bien escasas, teniendo en

${ }^{9}$ Vid. ad ex. en Canadá, la Foreing Extraterritorial Measures Act 1984, en vigor desde el 14 de febrero de 1985, (texto disponible en: https://laws-lois.justice.gc.ca/eng/acts/f-29/page-1.html) o en México, la Ley de Protección al Comercio y la Inversión de Normas Extranjeras que contravengan el Derecho Internacional, publicada en el Diario oficial mexicano, el 23 de octubre de 1996 (texto disponible en: http://www.diputados.gob.mx/LeyesBiblio/pdf/63.pdf).

${ }^{10}$ DO L núm. 309, de 29 de noviembre de 1996.

${ }^{11}$ Vid. Comisión Europea, Nota de orientación. Preguntas y respuestas: adopción de la actualización del estatuto de bloqueo, DO C núm. 277, de 7 de agosto de 2018.

${ }^{12}$ DO L núm. 199, de 7 de agosto de 2018.

${ }^{13}$ DO L núm. 199, de 7 de agosto de 2018.

${ }^{14}$ En el caso de España: Ley 27/1998, de 13 de julio, sobre sanciones aplicables a las infracciones establecidas en el Reglamento (CE) núm. 2271/96 del Consejo, de 22 de noviembre, relativo a la protección frente a la aplicación extraterritorial de la legislación de un país tercero, BOE núm. 167, de 14 de julio de 1998.

${ }^{15} \mathrm{Vid}$. D. VICH/I. HEREDIA, "Ley Helms-Burton: ¿qué implica y de qué mecanismos de defensa disponen los particulares y empresas de la UE?, https://www.garrigues.com/es_ES/noticia/ley-helms-burton-que-implica-y-de-que-mecanismos-de-defensadisponen-los-particulares-y.

${ }^{16}$ Vid. J. CARRASCOSA GONZÁLEZ, "La guerra transoceánica de Derecho internacional privado. Helms-Burton ataca de nuevo: una obra en siete actos”, http://accursio.com/blog/?p=883; ID., “¡Exprópiese! España, Cuba y playa esmeralda”, http://accursio. $\mathrm{com} / \mathrm{blog} / \mathrm{p}=1112$. 
cuenta el estatuto de bloqueo UE y la imposibilidad técnico-jurídica de que los tribunales, en este caso de la UE, apliquen una norma extraterritorial del calado de la Ley Helms-Burton. Por su parte, los afectados por la Ley Helms-Burton (demandados en EEUU) podrían, a su vez, reclamar una compensación mediante un procedimiento judicial entablado ante los tribunales de cualquier Estado miembro contra cualquier persona física o jurídica, o cualquier otra entidad, que haya causado los daños, o cualquier persona que actúe en su nombre o como intermediario, siempre y cuando posean activos o bienes en territorio $\mathrm{UE}^{17}$.

\section{Efectos colaterales de la Ley Helms-Burton en España}

9. En este cruce de demandas transoceánicas "sin cuartel", al que podrían arribar tanto el Título III de la Ley Helms-Burton como el estatuto de bloqueo UE, los términos de la litigación internacional quedan bien definidos. De tal forma que, antes de interponer una demanda ante tribunales de EEUU, los beneficiarios de la Ley Helms-Burton han de sopesar las posibilidades reales de éxito, teniendo en cuenta la futura ejecución de la sentencia, en EEUU o en el extranjero, así como el riesgo de afrontar una demanda ante tribunales de cualquier Estado miembro UE.

10. Pero, cuando parecía que todas las vías de litigación internacional estaban bien definidas en términos de eficiencia jurídica (costes/beneficios) ${ }^{18}$, se plantea ante los Tribunales españoles una demanda que hace tambalear la ecuación anteriormente planteada.

\section{Asunto Central Santa Lucía contra Meliá Hoteles: Hechos y cuestiones jurídicas planteadas}

11. Central Santa Lucía L. C. es una sociedad estadounidense, sucesora de la entidad Santa Lucía Company S.A. y de la sociedad civil Sánchez Hermanos. Estas dos empresas cubanas eran propietarias y explotadoras, en su día, de unos terrenos situados al norte de la isla de Cuba, en una zona conocida como "Ingenio Santa Lucía". Ambas sociedades se dedicaban a la explotación de la caña de azúcar. Tras la revolución castrista de 1 de enero de 1959, el nuevo régimen cubano decidió nacionalizar todos los bienes y empresas de personas naturales o jurídicas de nacionalidad cubana o constituidas conforme a la ley cubana, mediante la aprobación de la ley 890, publicada el día 15 de octubre de 1960. Dicha ley se aprobó en el marco de una política estatal de abolición total de la propiedad privada.

12. La aplicación de dicha ley provocó que el Estado de Cuba nacionalizase, entre otros muchos bienes, los terrenos de Santa Lucía Company SA y Sánchez Hermanos, que a partir de ese momento pasaron a ser propiedad de Cuba. Todo ello sin mediar compensación económica alguna.

13. Estos terrenos actualmente son propiedad de Gaviota S.A., una empresa pública cubana que, en su día, otorgó a Meliá Hoteles una autorización para gestionar y explotar los terrenos situados en Playa Esmeralda (integrados en la zona "Ingenio Santa Lucía"). En el marco de esta explotación se han construido en Playa Esmeralda los hoteles: Sol Río y Luna Mares y Paradisus Río de Oro. Meliá Hoteles ha estado obteniendo beneficios económicos por esta explotación "ilegítima" durante los últimos 20 años.

14. De ahí que, el 3 de junio de 2019, Central Santa Lucía decidiera interponer demanda ante los tribunales españoles contra dicha empresa española por considerar que ésta había obtenido un enriquecimiento ilícito durante todo este tiempo que ha durado su actividad hotelera en Playa Esmeralda.

\footnotetext{
${ }^{17}$ Sobre este derecho de compensación, conocido en el derecho anglosajón como cláusula claw-back, vid. F. J. GARCIMARTíN ALFÉREZ, "La reacción europea a las sanciones norteamericanas contra Cuba, Irán y Libia. El Reglamento no 2271/96 del Consejo, de 22 de noviembre de 1996", Gazeta Jurídica de la CE, 1997 B-120, pp. 19-23, en esp. pp. 21-22.

${ }^{18}$ Vid. F. J. Garcimartín AlFÉReZ, "La racionalidad económica del DIPr", Cursos de Derecho Internacional Privado VitoriaGasteiz, 2001, pp. 88-154.
} 
15. Admitida a trámite la demanda, Meliá Hoteles interpone declinatoria de jurisdicción y de competencia judicial internacional por entender que los tribunales españoles no pueden entrar a conocer de dicho asunto.

\section{Auto JPI de Palma de Mallorca, de 2 de octubre de 2019 y Auto AP de Palma de Mallorca, de 18 de marzo de 2020}

16. Por Auto de 2 de octubre de 2019, el Juzgado de Primera Instancia núm. 24 de Palma de Mallorca ${ }^{19}$ estima la declinatoria de jurisdicción y de competencia judicial internacional, y lo hace sobre la base de los siguientes argumentos.

17. Para resolver la controversia resulta necesario determinar cuáles son las concretas pretensiones de la parte actora y los fundamentos en los que se basa. Tal y como se ha expuesto con anterioridad, la demanda trae causa de la "confiscación" por parte del Estado cubano de unos terrenos, en los que posteriormente se autorizó la explotación hotelera a Meliá Hoteles. Esto ha provocado que la mencionada empresa española haya obtenido un enriquecimiento con causa ilícita, en tanto que ha estado obteniendo beneficios económicos de una explotación ilegítima. De ahí que, según la demandante, los beneficios obtenidos por la demandada deban ser considerados como frutos derivados de una posesión ejercitada de mala fe, según el art. 455 Cc español.

18. Para resolver las pretensiones de la demandante resulta necesario, por tanto, pronunciarse sobre la licitud o ilicitud del acto de nacionalización y sobre el derecho de propiedad o derecho de posesión de unos bienes de un Estado, algo que no es posible, según el JPI, por impedirlo la inmunidad de jurisdicción (art. 21.2 LOPJ, art. 36 LEC, arts. 2, 4 y 9-16 LO 16/2015²0).

19. Por otro lado, considera el JPI que los tribunales españoles tampoco tienen competencia judicial internacional para entrar a conocer de las pretensiones de Central Santa Lucía. Según el JPI, las pretensiones de la demandante se fundamentan en una acción real referida a un bien inmueble situado en Cuba, concretamente, en una acción reivindicatoria del derecho de propiedad o de posesión. Por tanto, en virtud del art. 24 del Reglamento (UE) núm. 1215/2012, de 12 de diciembre, del Parlamento Europeo, relativo a la competencia judicial, el reconocimiento y la ejecución de resoluciones judiciales en materia civil y mercantil (en adelante, Reglamento Bruselas I-bis) ${ }^{21}$ y del art. 22 LOPJ, los Tribunales españoles carecen de competencia judicial internacional por corresponder el conocimiento del asunto con carácter exclusivo a los tribunales del lugar donde está situado el bien inmueble.

20. Contra dicha resolución se interpone recurso de apelación por parte de Central Santa Lucía. Por Auto de 10 de marzo de 2010, la Audiencia Provincial de Palma de Mallorca ${ }^{22}$ revoca la resolución de instancia declarando la jurisdicción y la competencia judicial internacional de los tribunales españoles, y lo hace sobre la base de los siguientes argumentos:

21. En primer lugar, la Audiencia Provincial afirma la jurisdicción de los tribunales españoles por estimar que la demanda no se dirige contra el Estado cubano ni contra sus bienes. Esto es, para poder apreciar la "inmunidad de jurisdicción" resulta necesario que el en proceso intervenga como parte demandada un Estado (art. 49 y art. 51 LO 16/2015), y no es el caso.

\footnotetext{
${ }^{19}$ ECLI: ES: JPI: 2019:6A

${ }^{20}$ Ley Orgánica 16/2015, de 27 de octubre, sobre privilegios e inmunidades de los Estados extranjeros, las organizaciones internacionales con sede u oficinas en España y las Conferencias y Reuniones internacionales celebradas en España, $B O E$ núm. 258 , de 28 de octubre de 2015.

${ }^{21}$ DO L núm. 351, de 20 de diciembre de 2012.

${ }^{22}$ ECLI: ES: APIB: 2020:37A
} 
22. En segundo lugar, y por lo que respecta a la competencia judicial internacional, la Audiencia Provincial rechaza la calificación real de la pretensión ejercitada al no poder subsumirse en las acciones relativas a derechos reales inmobiliarios del art. 24.1 Reglamento Bruselas I-bis. Para ello, la acción debería tener por objeto determinar el alcance, la consistencia, la propiedad, la posesión de un bien inmueble o la existencia de otros derechos reales sobre esos bienes, y por otro, garantizar a los titulares de tales derechos la protección de las prerrogativas que les atribuye su título. En este caso concreto, la pretensión de la demandante se sustenta en un eventual enriquecimiento ilícito que se imputa a la parte demandada por la explotación de determinados establecimientos situados en los terrenos que se "confiscaron". Por tanto, no puede atribuirse carácter real a la pretensión ejercitada.

23. Para declarar la competencia judicial internacional de los tribunales españoles en este caso de enriquecimiento injustificado, resulta de aplicación el foro general del domicilio del demandado (art. 4 Reglamento Bruselas I-bis) y según la Audiencia Provincial, también el foro especial en materia de obligaciones extracontractuales (art. 7.2 Reglamento Bruselas I-bis). A igual conclusión llega el mencionado tribunal mediante la aplicación concurrente de los arts. 22.3 y art. 22 quinquies de la LOPJ.

\section{Auto JPI de Palma de Mallorca, de 6 de julio de 2020 y Auto JPI de Palma de Mallorca, de 30 de noviembre de 2020. The NeverEnding Story...}

24. Una vez determinada la jurisdicción y la competencia judicial internacional de los Tribunales españoles, se plantea por parte de Meliá Hoteles ante el JPI una cuestión incidental de previo pronunciamiento al considerar que la demanda presentada por Central Santa Lucía es un intento encubierto de esquivar los efectos del Estatuto de Bloqueo UE. También solicita sea elevada una cuestión prejudicial ante el TJUE para resolver las dudas de interpretación que pudieran surgir entre la mencionada normativa y la resolución de este caso concreto. Ambas cuestiones son desestimadas ${ }^{23}$.

25. Tras quedar resuelto este incidente, la demandada, Meliá Hoteles, presenta escrito de contestación a la demanda en el que, entre otras cuestiones, plantea una excepción procesal de falta de litisconsorcio pasivo necesario por entender que la acción planteada en la demanda no puede hacerse efectiva sino se ejercita también contra el Estado de Cuba. Dicha excepción es estimada ${ }^{24}$.

26. Según el JPI, resulta incompatible con la figura del litisconsorcio pasivo necesario (art. 12 LEC) celebrar un procedimiento judicial que tiene por objeto analizar la licitud de un acto de adquisición de la propiedad sin llamar a la persona o personas a las que afectará la sentencia que se dicte. De igual modo, y según el mencionado tribunal, resulta imposible reconocer a la demandante (Central Santa Lucía) un derecho real que justifique sus pretensiones y que resulta contradictorio con el derecho de propiedad del Estado cubano sin citar a éste para que puede compadecer en el procedimiento y defenderse. Por este motivo, la tramitación del procedimiento no puede continuar sin que sean citados como partes demandadas Cuba y Gaviota S.A., esta última como actual propietaria de los terrenos.

\section{Algunas consideraciones en torno al asunto Central Santa Lucía contra Meliá Hoteles}

27. Varias son las cuestiones jurídicas suscitadas por el asunto Central Santa Lucía contra Meliá Hoteles que se prestan al debate y análisis jurídico, entre ellas: a) la inmunidad de jurisdicción; b) la

\footnotetext{
${ }^{23}$ ECLI: ES: JPI:2019: 6a . Para un comentario a dicha resolución judicial, vid., J. L. IRIARTE ÁNGEL, “Continúan las decisiones sobre el Asunto Central Santa Lucía L.C contra Meliá Hotels International S.A. Notas al Auto del Juzgado de Primera Instancia $\mathrm{n}^{\circ} 24$ de palma de Mallorca de 6 de julio de 2020", Bitácora Millenium DIPr, núm 12, disponible en: http://www.millenniumdipr.com/ba-90-continuan-las-decisiones-sobre-el-asunto-central-santa-lucia-lc-contra-melia-hotels-internacional-sa-notas-alauto-del-juzgado-de-primera-instancia-no-24-de-palma-de-mallorca-de-6-de-julio-de-2020

${ }^{24}$ Puede consultarse el texto de dicha resolución en el siguiente enlace: https:/fernandezrozas.com/wp-content/ uploads/2020/12/Auto-Litisconsorcio.pdf
} 
competencia judicial internacional de los tribunales españoles para entrar a conocer del asunto: acción de enriquecimiento injustificado y litisconsorcio pasivo necesario; y c) la determinación del Derecho aplicable, si bien es cierto esta última cuestión no llega a plantearse "nunca" y "sorprendentemente" ante los órganos jurisdiccionales españoles ${ }^{25}$.

\section{Inmunidad de jurisdicción versus eficacia internacional de las nacionalizaciones}

28. Para poder resolver la pretensión de la parte demandante, que se sustenta en el enriquecimiento "ilícito" o injustificado que se imputa a la demandada por la explotación de determinados establecimientos sitos en los terrenos que, en su día, fueron "confiscados" por el Estado cubano, resulta inexcusable resolver una cuestión previa: la licitud o ilicitud del acto de nacionalización llevado a cabo por Cuba. Tanto el Juzgado de Primera Instancia como la Audiencia Provincial de las Islas Baleares coinciden en este punto, si bien es cierto discrepan en cuanto a su resolución.

29. Acierta, por completo, la Audiencia Provincial de las Islas Baleares al descartar, en este caso concreto, la inmunidad de jurisdicción. Baste recordar que la inmunidad de jurisdicción es un mecanismo que impide a los órganos jurisdiccionales de un Estado entrar a conocer de un litigio en el que sean demandados por un particular, un Estado extranjero o alguno de sus órganos, así como otros entes internacionales que gozan de tal inmunidad ${ }^{26}$.

30. En Derecho español, el art. 21. 2 LOPJ indica que, incluso en los casos en los que los tribunales españoles dispongan de un foro de competencia judicial internacional, "no conocerán de las pretensiones formuladas respecto de sujetos o bienes que gocen de inmunidad de jurisdicción o de ejecución de conformidad con las normas de Derecho Internacional Público". En este mismo sentido, la LO 16/2015, de 27 de octubre establece como requisito para apreciar de oficio la inmunidad de jurisdicción que se haya formulado demanda e incoado proceso contra alguno de los sujetos beneficiarios de la misma ante los órganos jurisdiccionales españoles (art. 49 y art 51 LO 16/2015).

31. En el asunto Central Santa Lucía contra Meliá Hoteles, la pretensión principal no se dirige en ningún caso contra el Estado cubano. Por tanto, la cuestión previa planteada no puede resolverse mediante la doctrina de la inmunidad de jurisdicción. Dicha cuestión debe ser afrontada desde el prisma de la eficacia internacional de los actos de nacionalización, tal y como se verá más adelante ${ }^{27}$.

32. De igual forma, y en coherencia con el planteamiento realizado, el litisconsorcio pasivo necesario, de haberlo, no debiera tener cabida en el ordenamiento jurídico español cuando uno de los demandados fuera un sujeto beneficiario de la inmunidad de jurisdicción. Tampoco cuando una de las pretensiones "ejercitadas" estuviera reservada al conocimiento exclusivo de los tribunales de otro Estado. Menos aún debiera un juez español requerir al demandante para que dirija su demanda contra unos sujetos que gozan de inmunidad de jurisdicción, máxime cuando el mismo tribunal, no otro, declinó su competencia inicialmente por esta misma razón.

\footnotetext{
${ }^{25}$ Vid. J. CARRASCOSA GONZÁLEZ, "Efectos legales en España de las expropiaciones de bienes inmuebles en Cuba. Un fascinante viaje por la geopolítica y el Derecho internacional privado", CDT, 2020, núm. 2, pp. 254-266; J. L. IRIARTE ÁNGEL, "La Ley HelmsBurton proyecta su sombra sobre la jurisprudencia española y la legislación de la Unión Europea", Bitácora Millenium DIPr, núm. 11, disponible en: http://www.millenniumdipr.com/ba-86-la-ley-helms-burton-proyecta-su-sombra-sobre-la-jurisprudenciaespanola-y-la-legislacion-de-la-union-europea; ID., "De nuevo sobre el problema de la competencia judicial internacional de los tribunales españoles para resolver litigios derivados de las nacionalizaciones cubanas. Reflexiones sobre el Auto de la Audiencia Provincial de Palma de Mallorca (Sec. $3^{\text {a }}$ ) de 18 de marzo de 2020", Bitácora Millenium DIPr, núm. 11, disponible en: http://www. millenniumdipr.com/ba-87-de-nuevo-sobre-el-problema-de-la-competencia-judicial-internacional-de-los-tribunales-espanoles-para-resolver-litigios-derivados-de-las-nacionalizaciones-cubanas; N. ZAMBRANA-TÉvAR, "The long tentacles of the Helms-Burton Act in Europe", September 6, 2019, disponible en: http://conflictoflaws.net/2019/the-long-tentacles-of-the-helms-burton-act-in-europe/

${ }^{26} \mathrm{Vid}$. A.-L. CAlVO CARAVACA/J. CARRASCOSA GONZÁLEZ, op. cit., nota 1, pp. 117-118.

${ }^{27} \mathrm{Vid}$. J. CARRASCOSA GONZÁLEZ, loc. cit., nota 25, pp. 257-263.
} 


\section{Competencia judicial internacional}

\section{A) Enriquecimiento injustificado}

33. Para determinar si los tribunales españoles tienen competencia judicial internacional para conocer de la pretensión de enriquecimiento injustificado ejercitada por Central Santa Lucía contra Meliá Hoteles, hay que estar a los que disponga el Reglamento Bruselas I-bis.

34. El Juzgado de Primera Instancia de Palma de Mallorca califica erróneamente la pretensión de la parte demandante al considerarla una acción real. Dicha calificación, conduce al mencionado tribunal a la aplicación del art. 24 Reglamento Bruselas bis-I, que en materia de derechos reales sobre bienes inmuebles atribuye el conocimiento exclusivo a los tribunales del Estado "miembro" donde estén sitos. Argumento que le sirve al mencionado tribunal, siguiendo con ello la tesis minoritaria de la "multilateralización" del art. 24 Reglamento I-bis, para descartar la competencia de los tribunales españoles al estar situado el bien inmueble en $\mathrm{Cuba}^{28}$.

35. Calificada correctamente por la Audiencia Provincial de las Islas Baleares la pretensión de la parte actora como una acción personal, la competencia judicial internacional ha de fundamentarse en el foro del domicilio del demando en un Estado miembro (art. 4 Reglamento Bruselas I-bis).

36. Llama la atención que la Audiencia Provincial aplique junto al foro general del domicilio del demando, el foro especial en materia de obligaciones extracontractuales (art. 7.2 Reglamento Bruselas I-bis), demostrando con ello un claro desconocimiento del funcionamiento de los foros especiales por razón de la materia, previstos en el Reglamento Bruselas I-bis. Dichos foros tienen por objeto desplazar al demandado con domicilio en un Estado miembro hacia los tribunales de otro Estado miembro. Sorprende, de igual forma, que el tribunal considere España como el "lugar donde se hubiere producido el hecho dañoso" 29 .

37. Finalmente, tanto el Juzgado de Primera Instancia como la Audiencia Provincial incurren en una práctica errónea, pero desgraciadamente muy habitual entre nuestros tribunales: el totum revolutum. Según dicha práctica, los tribunales españoles se declaran competentes porque así lo establece tanto un instrumento internacional, como también la LOPJ, o porque así se deduce al mismo tiempo de varios foros recogidos en la $\mathrm{LOPJ}^{30}$.

${ }^{28}$ El Reglamento Bruselas I-bis no ofrece una solución específica sobre la cuestión de saber si son competentes los tribunales de un Estado miembro en relación con los litigios relativos a materias objeto de competencia exclusiva de terceros Estados. Se han formulado varias teorías al respecto. La tesis oficial, sostenida por los Informes oficiales anejos al anterior Convenio de Bruselas y de Lugano, y seguida, aunque de forma indirecta por el TJUE, es la denominada "teoría anti-denegación de Justicia". Según dicha tesis, los tribunales de un Estado miembro deben conocer del asunto sin concurre cualquier otro foro previsto en el Reglamento Bruselas I-bis que les atribuya competencia judicial internacional. Junto a dicha teoría, se han propuesto otras, tales como: a) Teoría del efecto reflejo. Según esta teoría se trata de una cuestión no regulada por el Reglamento Bruselas I-bis, que debe ser resuelta, por tanto, por las normas de producción interna de cada Estado miembro; b) Teoría de la multilateralización del art. 24 Reglamento Bruselas I-bis. Por analogía a lo dispuesto en el Reglamento Bruselas I-bis, los tribunales de un Estado miembro deben declararse incompetentes cuando la materia objeto del litigio estuviera reservada al conocimiento exclusivo de los tribunales de un tercer Estado; c) Teoría mixta. Según esta tesis, la solución a este problema dependerá del lugar donde deba hacerse efectiva la futura sentencia que se dicte. Si ésta ha de ejecutarse en el territorio de un Estado miembro, cuyos tribunales poseen un foro previsto en el Reglamento Bruselas I-bis, no ha de procederse a la multilateralización del art. 24 del mencionado Reglamento. Si, por el contrario, la sentencia solo puede ejecutarse en un tercer Estado, los tribunales de un Estado miembro no deben declararse competentes, aunque dispongan de un foro de competencia judicial internacional. Dictar sentencias "inefectivas" supondría una vulneración de la tutela judicial efectiva (art. 24 CR/art. 6 CEDH). Vid. A. -L. CALVO Caravaca/J. Carrascosa GonzÁlez, Derecho Internacional Privado, Vol. II, $18^{a}$ ed., Comares, Granada, 2018, pp. 748-749.

${ }^{29}$ Sobre el funcionamiento de los foros especiales por razón de la materia en el Reglamento Bruselas I-bis, vid., con carácter general, A. -L. CALVO CARAVACA/J. CARRASCOSA GONZÁLEZ, op. cit., nota 28, pp. 793-796.

${ }^{30} \mathrm{Vid}$. A. -L. CALVO CaravaCa/J. CARRASCOSA GONZÁleZ, op. cit., nota 1, pp. 129-130. 


\section{B) Litisconsorcio pasivo necesario}

38. Disipada la cuestión de la competencia judicial internacional de los tribunales españoles para conocer de este asunto (acción de enriquecimiento injustificado), la parte demandada, tal y como se ha indicado con anterioridad, presenta en el escrito de contestación a la demanda una excepción de falta de litisconsorcio pasivo necesario por entender que la acción planteada en la demanda solo puede hacerse efectiva si se ejercita también contra el Estado de Cuba.

39. En primer lugar, llama la atención que el JPI de Palma de Mallorca haya resuelto la exceptio plurium litisconsortium planteada por Meliá Hoteles sin haber determinado previamente la competencia judicial internacional de los tribunales españoles para tramitar dicha excepción. Baste señalar, en este sentido, que el litisconsorcio pasivo necesario se engloba junto a otras figuras procesales en los supuestos tipificados de conexidad internacional ${ }^{31}$.

40. Los foros por conexidad procesal son aquellos que permiten extender la competencia judicial internacional que poseen los tribunales de un Estado para conocer de un determinado litigio a otro asunto u otros asuntos que presentan una especial vinculación con el primero. En estos casos, la atribución de competencia judicial internacional se fundamenta en la existencia de elementos comunes entre dos o más pretensiones (conexión/vinculación procesal). Los foros por conexidad procesal, a diferencia de los demás, no reflejan una vinculación directa e inmediata del litigio con el país cuyos tribunales son competentes, sino que se basan en una vinculación indirecta y mediata entre las pretensiones ejercitadas. En este sentido, a este tipo de foros se les denomina también foros derivados ${ }^{32}$.

41. Esto explica que los foros por conexidad procesal en cualquiera de sus modalidades, ya sean foros bilaterales por conexidad o foros multisubjetivos por conexidad, hayan suscitado tradicionalmente ciertos recelos por parte de la doctrina. Cierto es que a través de estos foros se consigue un doble objetivo: asegurar una buena administración de Justicia y, ante todo, prevenir el riesgo de decisiones inconciliables. Pero, no lo es menos que una inadecuada regulación de los mismos puede poner en peligro la tutela judicial efectiva y la seguridad jurídica al atribuir competencia judicial internacional a los tribunales de un Estado difícilmente previsible para una de las partes y carente de una mínima relación con el litigio ${ }^{33}$.

42. El Reglamento Bruselas I-bis tipifica diversos supuestos de conexidad procesal ${ }^{34}$. Concretamente, el art. 8. 1 Reglamento Bruselas I-bis regula el foro de pluralidad de demandados o litisconsorcio pasivo. Dicho foro permite al demandante presentar su demanda contra todos los demandados en un mismo proceso, ante los tribunales del Estado miembro donde tenga su domicilio cualquiera de ellos ${ }^{35}$.

\footnotetext{
${ }^{31}$ Sobre los foros por conexidad procesal, vid. M. AGUILAR BENíteZ DE LUGO, "La pluralidad de demandados en el Derecho internacional privado", Justicia, 1992, pp. 299-336; F. J. GARCIMARTín ALFÉREZ, Derecho internacional privado, $5^{\text {a }}$ ed., Civitas/ Thomson Reuters, Madrid, 2019, pp. 137-146; I. HEREdia CERVANTes, Proceso internacional y pluralidad de partes, Granada, Comares, 2002; A. QUIÑONES ESCÁMEZ, El foro de la pluralidad de demandados en los litigios internacionales, Madrid, Colex, 1996; M. VIRGós SORIAno/F. J. Garcimartín alférez, Derecho Procesal Civil Internacional. Litigación Internacional, $2^{\mathrm{a}}$ ed., Madrid, Civitas, 2007, pp. 207-227.

32 Vid. F. J. Garcimartín ALFÉreZ, op. cit., nota 31, p. 137.

${ }^{33}$ Vid. I. HEREDIA CERVANTES, op. cit., nota 31, pp. 8-9, pp. 299-312

${ }^{34}$ Vid. A.- L. Calvo CARACAVA/J. Carrascosa GOnZÁlez, op. cit., nota 29 pp. 796-801; F. F. Garau sobrino, “Artículo 6”, en A.L. CALVO CARAVACA (ED.), Comentario al convenio de Bruselas relativo a la competencia judicial y a la ejecución de resoluciones en materia civil y mercantil, Madrid, Universidad Carlos III de Madrid, Boletín Oficial del Estado, 1994, pp. 166-191, esp. 166-175; ID., "Los foros de vinculación procesal del art. 6 del Convenio de Bruselas. Anotaciones tras la firma del Convenio de adhesión de 1996", en A. BORRÁs (ED.), La revisión de los Convenios de Bruselas y Lugano de 1988 sobre competencia judicial y ejecución de resoluciones judiciales: una reflexión preliminar española, seminario celebrado en Tarragona, 30-31 de mayo de 1997, Barcelona, Marcial Pons, 1998, pp.325-339

${ }^{35} \mathrm{El}$ art. 8 Reglamento I-bis recoge diversos foros de competencia judicial internacional que permiten demandar a las personas domiciliadas en un Estado miembro por razón de conexidad. Junto al litisconsorcio pasivo (art. 8. 1), se tipifican también los siguientes supuestos: a) Ejercicio de acciones de garantía o para la intervención de terceros en el proceso (art. 8. 2); b)
} 
43. Para poder aplicar el foro previsto en el art. 8. 1 Reglamento Bruselas I-bis, es preciso que se cumplan diversos requisitos, entre ellos, que todos los demandados estén domiciliados en un Estado miembro. Si uno de los co-demandados no reside en un Estado miembro de la UE, el art. 8. 1 Reglamento Bruselas I-bis no puede utilizarse. La cuestión se regirá, en tal caso, por las normas de producción interna del Estado miembro cuyos tribunales conocen del asunto ${ }^{36}$. En el asunto Central Santa Lucía contra Meliá Hoteles, no procede por tanto la aplicación del art. 8. 1 Reglamento Bruselas I-bis.

44. En el caso de España, el sistema de competencia judicial internacional establecido en la LOPJ contiene un supuesto de conexidad procesal, concretamente, el foro de pluralidad de demandados. Según el art. 22 ter, aparatado 3 LOPJ, en tal caso "serán competentes los Tribunales españoles cuando al menos uno de los demandados tenga su domicilio en España, siempre que se ejercite una sola acción o varias entre las que exista un nexo por razón del título o causa de pedir que aconsejen su acumulación"37.

45. Dejando a un lado la desafortunada traslación que realiza el legislador español del art. 72 LEC (norma de competencia territorial) al art. 22 ter, apartado 3 LOPJ (norma de competencia judicial internacional inspirada en el Reglamento Bruselas I-bis), habría que plantearse en primer lugar, si existe o no litisconsorcio pasivo necesario en el asunto Central Santa Lucía contra Meliá Hoteles; y en segundo lugar, y en caso de que así fuera, si procede en este caso la aplicación del art. 22 ter, apartado 3 LOPJ para declarar competentes a los tribunales españoles, tendiendo en cuenta que uno de los codemandados goza de inmunidad de jurisdicción, y una de las pretensiones "ejercitadas" recae sobre una materia reservada a competencia exclusiva de los tribunales de un tercer Estado.

46. Respecto a la primera cuestión -existencia de litisconsorcio pasivo-, baste recordar que, en el ordenamiento jurídico español, la figura del litisconsorcio pasivo necesario tiene un origen jurisprudencial. No fue hasta la reforma del año 2000, cuando la mencionada figura quedó positivizada en el Derecho interno (arts. 12 y 72 LEC). El litisconsorcio pasivo necesario tiene lugar cuando un sujeto se ve obligado a emplazar a una pluralidad de personas como condición ineludible para la obtención de una decisión unitaria sobre el fondo. En Derecho español, el litisconsorcio pasivo necesario posee

Reconvención (art. 8. 3); c) Acumulación de acciones reales y contractuales (art. 8. 4). A ellos, habría que unir también el foro de conexidad marítimo (art. 9 Reglamento Bruselas I-bis) así como los supuestos contemplados en el art. 7. 3 (acumulación de acciones civiles y penales), arts. 11. 1 c), 13.1 y 3,14. 2 (conexidad procesal en materia de seguros), art. 18. 3 (reconvención en materia de contratos celebrados por consumidores) y art. 65 (litis denuntatio). ${ }^{35}$

${ }^{36}$ Para poder aplicar el foro de pluralidad de demandados previsto en el art. 8. 1 Reglamento Bruselas I-bis, resulta necesario además que concurran los siguientes requisitos: $1^{\circ}$ ) Las demandas planteadas estén "vinculadas estrechamente" entre sí, siendo éste un concepto propio del Reglamento Bruselas I-bis. Tal y como establece el art. 8.1 Reglamento Bruselas I-bis, existe "vinculación estrecha" cuando se aprecia que es oportuno tramitar y juzgar las pretensiones al mismo tiempo para evitar resoluciones que podrían ser irreconciliables si los asuntos se tramitaran por separado; $2^{\circ}$ ) Los demandados deben presentar alguna vinculación jurídica previa entre sí. Esta exigencia no aparece recogida expresamente en el Reglamento Bruselas Ibis, pero la doctrina la considera necesaria si se quiere respetar el principio de previsibilidad que ha de regir la determinación de la competencia judicial internacional respecto a todos los demandados, que se verán desplazados ante los tribunales del Estado donde está domiciliado uno de ellos; $3^{\circ}$ ) La existencia de litisconsorcio pasivo, necesario o voluntario, corresponde determinarla al Derecho procesal del país cuyos tribunales conocen del asunto; $4^{\circ}$ ) El foro de pluralidad de demandados no puede operar si existe un pacto de sumisión expresa entre el demandante y uno de los demandados. En tal caso, prevalece en todo caso el art. 25 Reglamento Bruselas I-bis. $5^{\circ}$ ) Tampoco pude operar dicho foro multisubjetivo si una de las pretensiones ejercitadas por el demandante está reservada al conocimiento exclusivo de los tribunales de un Estado miembro, distinto al domicilio de uno de los demandados. En tal supuesto, el art. 24 Reglamento Bruselas I-bis prevalece sobre todos los demás foros del Reglamento. Vid. A.- L. Calvo Caracava/J. Carrascosa GOnZÁlez, Derecho Internacional Privado, Vol. II, $18^{\mathrm{a}}$ ed., Granada, Comares, 2018, pp. 796-801; M. VIRGÓS SORIANO/F. J. GARCIMARTíN ALFÉREZ, op. cit., nota 31, pp. 211-216; I. HEREDIA CERVANTES, op. cit., nota 31, pp.199-244.

${ }^{37}$ No se alcanza a entender como el legislador español, no ha incorporado en el sistema de competencia judicial internacional de producción interna, claramente inspirado en el Reglamento Bruselas I-bis, otros foros por conexidad procesal como la intervención de terceros, la reconvención o la acumulación de acciones. Tampoco tiene explicación alguna, la traslación literal del art. 72 LEC, norma de competencia interna, al art. 22 ter, apartado 3 LOPJ, norma de competencia judicial internacional inspirada en las normas de Derecho internacional privado europeo, especialmente por lo que al concepto de "vinculación estrecha" se refiere. 
una naturaleza materia ${ }^{38}$. Se fundamenta en el carácter inescindible de la relación jurídica objeto del proceso. En este sentido, cabe distinguir dos tipos de situaciones litisconsorciales: aquellas previstas en las leyes (litisconsorcio propiamente necesario) y aquellas otras forjadas por la jurisprudencia del TS

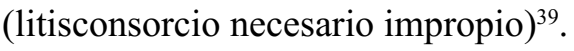

47. El litisconsorcio pasivo necesario impropio se justifica en la necesidad de evitar que puedan ser afectados por la resolución judicial quienes no fueron oídos ni vencidos en juicio, así como impedir la posibilidad de que se produzcan sentencias contradictorias sin posible ejecución. Situaciones que solo se dan respecto a terceros intervinientes directamente en la relación jurídico-material debatida, pero no respeto a aquellos otros a los que solo les afecta de una forma indirecta, refleja, mediata o prejudicial por simple conexión.

48. Con el litisconsorcio pasivo necesario se trata de evitar que personas no litigantes se vean afectadas por la sentencia recaída en un proceso en el que no han sido parte. En otras palabras, persigue evitar que la sentencia recaída en un proceso pueda afectar de forma directa y perjudicial, y con los consiguientes efectos de cosa juzgada a alguna o algunas de las personas que no hayan sido parte en el proceso ${ }^{40}$.

49. El litisconsorcio pasivo necesario no es apreciable cuando los posibles efectos hacia terceros se producen con carácter reflejo, por una simple o mediata conexión, o porque la relación material sobre la que recaen produce una declaración que solo les afecta con carácter prejudicial o indirecto. En estos casos, la intervención en el litigio podrá ser voluntaria pero no necesaria, en tanto que la extensión de los efectos de cosa juzgada no les afecta ni se produce para ellos indefensión.

50. En el asunto Central Santa Lucía contra Meliá Hoteles no concurren las circunstancias necesarias para estimar un litisconsorcio pasivo necesario. Primero, el tercero (Estado de Cuba) no interviene directamente en la relación jurídico-material debatida (enriquecimiento injustificado), solo lo hace de manera prejudicial e indirecta. Segundo, la relación jurídica objeto del proceso no presenta carácter inescindible respecto a una pluralidad de sujetos. Tercero, la declaración que pueda realizar el juez respecto a los terceros les afecta con carácter prejudicial o indirecto (licitud/ilicitud del acto de nacionalización), por tanto, la sentencia que se dicte no producirá efectos de cosa juzgada ni les producirá indefensión para ellos.

51. En tal caso, nos hallamos ante una cuestión previa a la cuestión principal que actúa como antecedente lógico de esta, y que debe resolverse por ello, de forma anticipada para resolver el objeto del proceso. Por tanto, la única forma de encauzar este asunto en sus debidos términos jurídicos pasa por resolver la cuestión previa planteada (licitud o ilicitud del acto de nacionalización) de la cual depende la resolución de la pretensión principal (enriquecimiento injustificado), teniendo en cuenta que la decisión alcanzada por el tribunal español respecto al tercero o terceros (Estado de Cuba y Sociedad Gaviota) no produce efectos de cosa juzgada frente a los mismos.

52. El motivo por el que Meliá ha obtenido el enriquecimiento injustificado que ha generado el derecho de la parte actora a reclamar los frutos obtenidos por la explotación hotelera, proviene de que la demandada de manera consciente se está beneficiando económicamente de una confiscación de bienes llevada a cabo en contra de las normas de derecho internacional y, por tanto, hecha de forma ilícita. El hecho que convierte en injustificado el enriquecimiento de Meliá es la propia ilicitud del acto de nacionalización, no los negocios jurídicos concretos que posteriormente Cuba haya celebrado sobre dichos

\footnotetext{
${ }^{38}$ Siendo esto así, desde el punto de vista del DIPr español, la existencia de litisconsorcio pasivo se hará depender de la lex causae, norma que rige el fondo del asunto.

${ }^{39} \mathrm{Vid}$. I. HEREDIA CERVANTES, op. cit., nota 31, pp. 283-297, pp. 341-351.

${ }^{40}$ Vid., entre otras: ;STS 25 de octubre de 1993; STS 31 de enero de 1995; STS 10 de junio de 1996; STS 18 de septiembre de 1996; STS de 23 de febrero de 1998; STS 27 de febrero de 1998; STS 8 de junio de 1998; STS 11 de junio de 1998; STS 18 de septiembre de 1998; STS 22 de octubre de 1998; STS 24 de noviembre de 1998; STS 28 de diciembre de 1998; STS 29 de febrero de 2000.
} 
terrenos. De esta manera, la valoración de la licitud o ilicitud del acto de nacionalización que provoca que los terrenos controvertidos pasen a ser propiedad del Estado cubano es un requisito previo y fundamental en la formulación y resolución de las pretensiones de la demandante. Para ello no resulta necesaria la intervención del Estado Cubano en el procedimiento. Como se verá más adelante, la cuestión previa debería ser afrontada por parte de nuestros tribunales desde el prisma de la eficacia internacional de los actos de Estado.

53. En el supuesto de existir litisconsorcio pasivo necesario, la segunda cuestión que debería plantearse giraría en torno a la posible aplicación del art. 22 ter, apartado 3 LOPJ para fundamentar la competencia judicial de los tribunales españoles.

54. El foro de pluralidad de demandados regulado en el art. 22 ter, apartado 3 LOPJ no puede operar ni cuando una de las pretensiones se dirige contra un sujeto que goce de la inmunidad de jurisdicción, lo impide así el art. 36. 2. $1^{\circ}$ LEC, ni cuando una de las pretensiones que se ejerciten verse sobre una materia reservada a la competencia exclusiva de un tercer Estado. Admitir, en este último supuesto, lo contrario conduciría a nuestros tribunales a dictar una sentencia inejecutable y, por ende, a una tutela judicial "inefectiva", en contra de lo establecido en el art. 24 CE/art. 6 CEDH.

55. Finalmente, llama la atención la contradicción manifiesta en la que incurre el JPI de Palma de Mallorca que en Auto de 2 de septiembre de 2019, admite la declinatoria de jurisdicción y de competencia judicial internacional, revocada muy acertadamente por la AP en Auto de 18 de marzo de 2020, y que vuelve ahora y con los mismos argumentos que fueron rechazados por el órganos jurisdiccional superior a estimar la excepción de litisconsorcio pasivo necesario sin plantearse previamente: $1^{\circ}$ ) la competencia judicial internacional de los tribunales españoles para estimar la situación de litisconsorcio pasivo necesario planteada; $2^{\circ}$ ) requiriendo a la parte actora a dirigir su demanda contra un tercero/ terceros, a sabiendas de que dichos sujetos gozan de inmunidad de jurisdicción. ¿Podría explicar alguien tal despropósito jurídico?

\section{Cuestiones de Derecho aplicable}

56. En el asunto Central Santa Lucía contra Meliá Hoteles, no se plantea controversia alguna en torno a la determinación de la ley aplicable. La demandante fundamente sus pretensiones con base al Derecho español, concretamente art. 455 Cc.

57. Teniendo en cuenta el carácter imperativo de las normas de conflicto (art. $12.6 \mathrm{Cc}$ ), surge de inmediato la cuestión de dilucidar cual es la ley aplicable a este asunto.

58. El Reglamento (CE) núm. 864/2007, de 11 de julio, del Parlamento Europeo, relativo a la ley aplicable a las obligaciones extracontractuales (en adelante, Reglamento Roma II) ${ }^{41}$, contiene una norma especial para el enriquecimiento injustificado (art. 10). No obstante, el Reglamento Roma II no resultaría de aplicación en tanto que los hechos generadores del daño se produjeron con anterioridad a la entrada en vigor del mencionado texto legal (art. 31 y art. 32 Reglamento Roma II).

59. Por tanto, para determinar el derecho aplicable habría que recurrir al art. 10.9 Cc español, que en su apartado 3, dispone que: "en el enriquecimiento sin causa se aplicará la ley en virtud de la cual se produjo la transferencia del valor patrimonial en favor del enriquecido"42. Por tanto, la pretensión ejercitada por Central Santa Lucía contra Meliá Hoteles ante los tribunales españoles debería regirse

\footnotetext{
${ }^{41}$ DO L núm. 199, de 31 de julio de 2007.

${ }^{42} \mathrm{Vid}$. M. A. amores conrradi, “Art. 10. 9”, en M. albaladejo/s. díaz alabart (Dirs.), Comentarios al Código Civil y Compilaciones Forales, Madrid, Edersa, 1995, pp. 729-769; J. A. Carrillo Salcedo, “Art. 10. 9”, en M. albaladejo (Dir.), Comen-
} 
por el Derecho cubano. Cuestión esta que nos conduciría a tratar el espinoso problema de la alegación y prueba del Derecho extranjero, algo que desbordaría el objeto de este trabajo.

\section{Eficacia internacional de las nacionalizaciones}

\section{Consideraciones previas}

60. Cualquier Estado puede adoptar diferentes medidas en orden a adquirir bienes de los particulares, -personas físicas y/o jurídicas, ya sean nacionales o extranjeras-, siempre que estén situadas en su territorio. Tales medidas son, principalmente: la nacionalización, la expropiación y la confiscación. A pesar de que desde la perspectiva del Derecho internacional privado gocen de un tratamiento análogo, lo cierto es que son conceptos diferentes ${ }^{43}$. En general, se entiende que la confiscación es una medida de carácter penal, y que como tal, no conlleva compensación; por otra parte, la expropiación se caracteriza por ser un acto administrativo dirigido a bienes específicos, y que siempre implica una indemnización, aspectos que la diferencian de la nacionalización, medida legislativa que afecta a todo el sistema económico de un país, o a sociedades globalmente consideradas, pero no a bienes aislados, y no siempre va acompañada de la debida compensación ${ }^{44}$.

61. El Estado cubano, que es el caso que aquí nos ocupa, llevó a cabo una nacionalización general de su economía, mediante la Ley 890 de 13 de octubre de 1960, como consecuencia de un cambio en la estructura política y económica del país. Aunque no se previó la correspondiente indemnización en la ley antes citada, sí se hizo en la Ley 956 de 24 de agosto de 1961. Sin embargo, dicha compensación nunca llegó a hacerse efectiva ${ }^{45}$.

62. El tratamiento jurídico-internacional de las nacionalizaciones es ciertamente complejo: deben combinarse tanto una perspectiva de Derecho internacional público como una perspectiva de Derecho internacional privado ${ }^{46}$. En virtud de la primera, cada Estado es competente para tomar las medidas de nacionalización que estime oportunas siempre que estás sólo afecten a bienes dentro de sus fronteras. Estas medidas tendrán plenos efectos en dicho Estado. Por otro lado, el Derecho internacional privado se encarga de fijar las condiciones para proceder a la validez extraterritorial de los actos de nacionaliza-

tarios al Código civil y Compilaciones Forales, Tomo I, Jaén Edersa, 1978, pp. 360-369; L. ESTEVE GONZÁLEZ, Ley aplicable al enriquecimiento sin causa eb ek Derecho internacional privado español, Madrid, Eurolex, 1998.

${ }^{43}$ Esta diferenciación conceptual tendrá sus efectos a la hora de analizar su conformidad con el orden público internacional español, como se verá más adelante.

${ }^{44}$ Acerca de la diferenciación entre estos tres conceptos, vid. P. ADRIAANSE, Confiscation in Private International Law, The Hague, 1956, pp. 5-9, 96-97; M. Agullar navarro, (dir), Derecho Civil Internacional, Vol. II, Madrid, 1975, pp. 712; M. BODGAN, Expropriation in Private International Law, Lund, 1975, pp. 12-13; M. DOMKE., "Foreign nationalizations", AJIL, Vol. 55, $\mathrm{n}^{\circ} 3$, 1961, pp. 587-590; T. HEFTI , La protection de la propiété étrangère en droit international public, Neuchâtel, 1989, pp. 78-80; F. KNOEPFLER, «Les nationalisations françaises face à l'ordre juridique suisse», ASDI, vol. XXXIX, 1983, pp. 149-153; F. MUNCH, "Les effets d'une nationalisation à l'ètranger", $R C A D I$, vol. 98, 1959, pp. 418-422; s. PETREN, "La confiscation des biens étrangers et les réclamations internationales auxquelles elle peut donner lieu", RCADI, vol.109, 1963, pp.493-496; A. QUIÑONES ESCAMEZ, Eficacia Internacional de las nacionalizaciones: nombre comercial y marcas, Madrid, 1988, pp. 23-24; ID., "Problemas jurídico-internacionales relativos a la propiedad de la marca Dry Sack y otras surgidos a raíz de la expropiación del holding Rumasa", Diario La Ley, 1984, tomo 3, pp. 816; A. SADEK EL-KOCHERI, "Les nationalisations dans les pays du Tiers monde devant le juge occidental", RCDIP, LVI, 1967, pp.249-251; M. SAVATIER, "Les nationalisations en droit international privé", Travaux du Comité français de Droit international privé 1946-1948, París, 1951, pp. 50-51; B. A. WORTLEy, Expropiation in Public International Law, Cambridge, 1959, pp. 36-37. A su vez, se han distinguido también 3 tipos de nacionalizaciones: a) las realizadas por países occidentales, en las cuales siempre se acuerda la debida compensación; b) las ejecutadas por la Unión Soviética, que por razones ideológicas contra la propiedad privada no han ido acompañadas de indemnización alguna (sobre la mismas vid. B. A. WORTLEY, op. cit., pp.115-117) $\mathrm{y} ; \mathrm{c}$ ) las llevadas a cabo como consecuencia de los procesos de descolonización, las cuales han conllevado compensación (vid. A. SADEK EL-KOCHERI, loc. cit., pp. 251-253). Por ello, las nacionalizaciones que no han ido acompañadas de indemnización, a pesar de estar previstas en las leyes nacionalizadoras o en convenios, equivalen, de hecho, a las confiscaciones, vid. T. HEFTI, op. cit., p.133.

45 Vid. C. GARREAU DE LOUBRESSE, "Les nationalisations cubaines", AFDI, 1961, pp. 215-226.

${ }^{46}$ Sobre la relación de ambas perspectivas en materia de nacionalizaciones, vid. M. SAVATIER, loc. cit., nota 44, pp. 49-50. 
ción, ya que el Derecho internacional público no obliga al resto de Estados a reconocer tales medidas, sino que cada Estado es libre de reconocer o no efectos extraterritoriales a los actos de otros Estados ${ }^{47}$.

63. Con este telón de fondo, y teniendo como referente la cuestión previa planteada ante los tribunales españoles en el asunto Central Santa Lucía contra Meliá Hoteles, se tratará de examinar si la nacionalización llevada a cabo por el Estado cubano reúne las condiciones necesarias para obtener eficacia jurídica en España.

\section{Perspectiva de Derecho Internacional Privado}

64. Para determinar la eficacia internacional de las nacionalizaciones, la doctrina más autorizada propone verificar, ante la ausencia de una regulación específica al respecto, el cumplimiento de dos condiciones: $1^{\circ}$ ) la competencia internacional del Estado nacionalizador para adoptar tal medida y; $2^{\circ}$ ) la no contrariedad de la medida de nacionalización con el orden público internacional ${ }^{48}$.

\section{A) Competencia internacional del Estado que dicta el acto público expropiatorio}

65. En función del tratamiento jurídico que se otorgue a la naturaleza del acto de nacionalización, cabe distinguir grosso modo dos mecanismos para efectuar el control de la competencia internacional del Estado que dicta el acto público expropiatorio: a) el principio de territorialidad; b) el principio de vinculación efectiva.

a) Principio de territorialidad

66. Los métodos tradicionalmente utilizados en orden a examinar la competencia internacional del Estado que dicta el acto público expropiatorio han sido: el principio de la territorialidad, aplicado en el Derecho continental, y la doctrina del Act of State, propio del Derecho anglosajón. Aunque guarden ciertas diferencias, lo cierto es que ambos mecanismos basan la eficacia internacional de la nacionalización en la localización del bien litigioso dentro de la esfera de soberanía del Estado nacionalizador, esto es, dentro de su territorio ${ }^{49}$.

67. El Estado tiene una competencia exclusiva en su territorio. Por tanto, las medidas de nacionalización no pueden afectar más que a los bienes situados en el territorio del Estado nacionalizador. En cualquier caso, los demás Estados son libres para reconocer o no, efectos a los actos de otros Estados. El principio de territorialidad se traduce, desde el punto de vista conflictual, en la determinación de la ley

${ }^{47}$ Vid. F. BOULANGER, Les nationalisations en droit international privé comparé, París, Economica, 1975, p. 53; A. SADEK EL-KOCHERI, loc. cit., nota 44, pp. 254-255; B. A. WORTLEY, op. cit., nota 44, p. 17. La mayoría de la doctrina destaca la falta de utilidad del Derecho internacional público para resolver el problema de la eficacia extraterritorial de las nacionalizaciones dejando tal extremo al Derecho internacional privado. Sin embargo, A. K. BOYE en su tesis sobre las nacionalizaciones otorga un papel más relevante al Derecho internacional público, será éste el que recogerá las condiciones de la eficacia internacional de las nacionalizaciones, para dejar al Derecho internacional privado la determinación de dicha eficacia (vid. L'acte de nationalisation, Dakar, 1979, pp. 127-134, 175-199).

48 Vid. A.-L. Calvo CaRAVACA/J. CaRRASCOSA GONZÁLEZ, op. cit., nota 29, pp. 1221-1227.

${ }^{49}$ Mientras que el principio de territorialidad utiliza una técnica conflictual para situar los bienes nacionalizados, la doctrina del Act of State emplea un método unilateral, fundamentado en la división de poderes, concretamente en la idea de que el poder judicial no debe inmiscuirse en las tareas propias del poder ejecutivo, como son las relaciones diplomáticas con otros Estados. De ahí que se establezca que ningún tribunal puede denegar efectos a una nacionalización siempre que el Estado tome esta medida respecto de bienes situados en su territorio. Al igual que ocurre en la jurisprudencia continental, en la jurisprudencia anglosajona también es común alegar la excepción de orden público para denegar efectos a las nacionalizaciones. Vid. I. GUARDANS I CAMBÓ, Contrato internacional y Derecho imperativo extranjero: de la jurisprudencia comparada al Convenio de Roma de 19-6-1980, Pamplona, Aranzadi, 1992, pp.236-238; A. QUIÑONES ESCAMEZ, op. cit., nota 27, pp. 42-54; I. SEIDL-HOHENVELDERN, "Expropiaciones de Estados extranjeros y tribunales internos", Revista de Estudios Políticos, 1966, pp. 110-124. 
de situación del bien como criterio de verificación de la competencia internacional del Estado. Esta es la posición seguida tradicionalmente y de forma mayoritaria por doctrina y jurisprudencia en el derecho comparado, incluido el Tribunal Supremo español ${ }^{50}$.

b) Principio de vinculación efectiva

68. La doctrina más reciente, sin embargo, ha sometido a constantes críticas la utilización que la jurisprudencia ha realizado del método conflictual en esta materia. Partiendo de la idea de la «unidad económica» de la empresa se intenta flexibilizar el reconocimiento extraterritorial de la medida de nacionalización, subsumiendo esta cuestión en el ámbito del conflicto de jurisdicciones (P. Mayer ${ }^{51}-$, o en el de conflicto de autoridades (A. K. Boye) ${ }^{52}-$.

69. En los litigios derivados de una nacionalización, no se trata de acudir al conflicto de leyes para elegir la norma aplicable, pues ya existe una: la ley del Estado nacionalizador, de manera que tan sólo habrá que determinar la aceptación o rechazo de los efectos de ésta en el foro ${ }^{53}$. Desde esta perspectiva, si el bien nacionalizado es una empresa, siguiendo el criterio de unidad económica, los bienes dependientes de la misma deben considerarse también nacionalizados con independencia del lugar donde estén situados. Por tanto, es necesario determinar el vínculo económico entre sociedad y Estado nacionalizador. En este sentido, debe prestarse atención al lugar donde la empresa realiza su actividad económica, su objeto social. Si es dentro del territorio del Estado nacionalizador, la nacionalización deberá surtir efectos no sólo respecto de la sociedad, sino respecto de todos sus bienes, ya que estos también se utilizan para desarrollar tal actividad.

\section{B) Conformidad con el orden público internacional español}

70. Una vez que se ha comprobado la competencia del Estado nacionalizador para tomar tal medida de privación de la propiedad privada, la segunda condición a cumplir, si se quiere otorgar eficacia extraterritorial a una nacionalización, es la conformidad con el orden público internacional español.

71. Ahora bien, la función que cumple el orden público internacional en materia de nacionalizaciones está condicionada por el mecanismo utilizado para verificar la competencia internacional del Estado nacionalizador, pudiéndose distinguir dos supuestos: a) excepción al normal funcionamiento de la norma de conflicto; b) condición de validez extraterritorial del acto de nacionalización.

a) Orden público internacional como excepción al normal funcionamiento de la norma de conflicto

72. Cuando se utiliza la técnica conflictual, y por tanto el principio de territorialidad, para verificar la competencia internacional del Estado nacionalizador, como hace la mayor parte de la doctrina y de

\footnotetext{
${ }^{50}$ En lo que respecta al principio de territorialidad y su influencia en la negación de la eficacia extraterritorial de las nacionalizaciones, vid. T. BALlarino, Diritto internazionale privato, Padova, 1982, pp. 844-845; H. BATTIFFOL/P. LAGARDE, Droit international privé, $7^{\mathrm{a}}$ ed., T. II, Paris, 1983, pp. 186-193; I. GUARDANS I CAMBÓ, op. cit., nota 32, pp. 233-236; A. QUIÑONES ESCAMEZ, op. cit., nota 44, pp. 35-42.

${ }^{51}$ P. MAYER, La distinction entre règles et décisions et le droit international privé, Paris, 1973.

${ }^{52}$ A. K. BOYE, L'acte de nationalisation, Dakar, 1979.

${ }^{53}$ P. MAYER entiende que el método del conflicto de leyes debe utilizarse con las reglas, mientras que las decisiones, como son las nacionalizaciones, deben tratarse a través del método del conflicto de jurisdicciones, (op. cit., pp.102-121). Por su parte, A. K. BOYE no habla de decisión, sino de acto. Según esta construcción doctrinal, al igual que la defendida por P. MAYER, los tribunales sólo pueden decidir si aceptan o rechazan la nacionalización, si bien, éstos se encuentran dentro del ámbito del conflicto de autoridades, no de jurisdicciones. En todo caso, los tribunales deben dilucidar si la autoridad que dictó dicho acto era o no competente. Para ello, se tendrá en consideración la idea de la unidad económica que supone una sociedad. Aunque, a diferencia de la anterior tesis, en esta última no se descarta la aplicación de la norma de conflicto como una herramienta de control a la hora de analizar las condiciones para otorgar eficacia extraterritorial a las nacionalizaciones, si bien, su utilización sería extraordinaria. Vid. L'acte...op. cit., pp. 150-173.
} 
la jurisprudencia en derecho comparado, el orden público internacional queda completamente desnaturalizado. Y ello, por dos razones: $1^{\text {a }}$ ) si el bien litigioso se localizada, mediante la aplicación de la norma de conflicto del foro, fuera del territorio del Estado nacionalizador, no quedará afectado por la medida de nacionalización; $2^{\mathrm{a}}$ ) como consecuencia de lo anterior, el orden púbico no aparece como excepción al normal funcionamiento de la norma de conflicto, sino como condición para aceptar o rechazar efectos extraterritoriales a la nacionalización. Afirmación esta que queda totalmente reforzada en aquellos litigios relativos a las marcas de empresa ${ }^{54}$.

73. La situación de las marcas en el lugar de registro y protección conduce a la aplicación de la ley del foro. Si, en virtud de la protección territorialista, procede aplicar en general la ley del lugar de su registro y no la ley del país de origen -país nacionalizador-, no cabe en ningún modo aplicar la excepción de orden público (art. 12. $3 \mathrm{Cc}$ ). El recurso a dicho mecanismo resulta del todo superfluo. Aun así, resulta del todo llamativo que los tribunales recurran de forma reiterada a dicho mecanismo.

74. Salvo en aquellos casos en los que la norma de conflicto del foro conduce a la aplicación de la ley del Estado nacionalizador, cabe afirmar que la técnica conflictual no se adapta, a la naturaleza y funcionamiento de las nacionalizaciones. Su verdadera función es localizar el bien y verificar así la competencia territorial del Estado nacionalizador, designando tan sólo en un sentido formal la ley aplicable, pues a la hora de analizar el orden público, los tribunales no toman como referencia la ley designada por la norma de conflicto, sino que toman en consideración la ley nacionalizadora. Algo que confirma que, de facto, el orden público internacional es utilizado por los tribunales como una condición para aceptar o rechazar efectos internacionales a las nacionalizaciones realizadas por otros Estados.

75. Este planteamiento, -técnica conflictual y desnaturalización de la excepción de orden público internacional, es el que ha seguido el Tribunal Supremo español en las dos ocasiones en que ha tenido que pronunciarse sobre las nacionalizaciones en Cuba: Sentencia de 25 de septiembre de $1992^{55}$ y Sentencia de 30 de diciembre de $2010^{56}$. En ambos casos, aunque con importantes diferencias entre ellos, se disputaba la propiedad de una marca registrada en España. El Tribunal Supremo tras no reconocer la nacionalización de la sociedad cubana y confirmar la adquisición fraudulenta de la marca española por parte del Estado cubano -lo cual bastaría para denegar la eficacia de la nacionalización cubana en España-, añade la falta de conformidad de dicha nacionalización con el orden público por la inexistencia de una indemnización económica a favor de los perjudicados ${ }^{57}$. Es importante matizar que el Tribunal Supremo, en ambos casos, podía haber alegado la excepción de orden público respecto de la nacionalización de la sociedad, a la cual, según la técnica conflictual clásica, se le aplicaba la ley cubana, pero de ningún modo a la marca, sita en España, tal y como el propio Tribunal Supremo dice, sometida a la ley española ${ }^{58}$.

${ }^{54}$ La utilización del orden público es estos casos como «cajón de sastre» por parte de los tribunales evidencia la existencia más bien de intereses políticos, económicos y sociales del Estado requerido, vid. A. QUIÑONES ESCAMEZ, op. cit., nota 44, pp. 257-267.

${ }^{55}$ RJ $\backslash 1992 \backslash 7325$. Vid. comentarios a esta sentencia en: F. J. GARCIMARTín AlfÉrez, " 25 de septiembre de 1992. Nacionalización extranjera. Efectos sobre marcas registradas en España. Contrariedad con el orden público", Cuadernos Civitas de Jurisprudencia Civil,1992, núm. 30, pp.883-884; P. JIMÉNEZ BLANCO, "Comentario a la STS (Sala 1ª) de 25 de septiembre de 1992", REDI, 1994, núm. 1, pp. 382-383.

${ }^{56}$ ECLI:ES:TS:210:7666. Para un comentario a esta sentencia, vid. A. HERNÁNDEZ RODRÍGUEZ/c. MACHO GÓMEZ, "Eficacia internacional de las nacionalizaciones sobre las marcas de empresa: el asunto "Havana Club" ante los tribunales españoles", CDT, 2012, núm. 2, pp. 159-176.

${ }^{57}$ Vid. STS (Sala de lo Civil), de 25 de septiembre de 1992, FJ 3ㅜ; STS (sala de lo Civil), de 30 de diciembre de 2010, FJ 11.

${ }^{58} \mathrm{Vid}$. A pesar del grave error a la hora de entender la función de la excepción de orden público en el ámbito del conflicto de leyes, ha sido un argumento muy utilizado en toda la jurisprudencia relativa a la nacionalización de las marcas: Tribunal de Apelación de París, de 25 de junio de 1958, caso «Hardmuth Kok-I-Noor»; Tribunal de Apelación de Turín, de 17 de junio de 1958, caso «Hardmuth Kok-I-Noor»; Tribunal de Distrito de Oslo, de 11 de julio de 1959, caso «Hardmuth Kok-I-Noor»; Tribunal de Gran Instancia de París, de 15 de diciembre de 1971 «caso Zeiss»; Tribunal de Apelación de París, de 9 de julio de 1975, «caso Zeiss»; Tribunal del Distrito de Nueva York, de 7 de noviembre de 1968, «caso Zeiss»; Tribunal de Apelación de Milán, de 10 de agosto de 1956, «caso Zeiss»; Tribunal de Milán, de 14 de junio de 1965, «caso Zeiss»; Tribunal de París, de 19 de marzo de 1963 «caso Agfa»; Tribunal Supremo holandés, de 18 de enero de 1965, «caso Kjllberg»; Tribunal Supremo 
b) Orden público internacional como condición de validez extraterritorial del acto de nacionalización

76. Desde un enfoque competencial, -conflicto de jurisdicciones o autoridades-, y aceptando por tanto la competencia personal del Estado para nacionalizar bienes, resulta absolutamente necesario analizar la compatibilidad de la nacionalización con el orden público internacional. Debe tenerse en cuenta que, en este caso, el orden público no constituye una excepción al normal funcionamiento de la norma de conflicto, sino una condición a la eficacia extraterritorial de la nacionalización.

77. Desde esta perspectiva, orden público como condición de la validez extraterritorial del acto de nacionalización, se debe concretar qué elementos configuran tal concepto en dicha materia. Según la doctrina, se entiende que los principios configuradores del orden público internacional español en materia de nacionalizaciones son: a) la existencia de una causa de interés general; b) un procedimiento de privación de la propiedad que permita la defensa jurídica del expropiado; c) la existencia de una indemnización justa; d) que no haya existido discriminación o represalia ${ }^{59}$; y e) que el caso tenga suficiente vinculación con el Estado requerido,- orden público internacional de proximidad- ${ }^{60}$.

78. En cuanto a la primera condición, -existencia de una causa de interés general-, la voluntad de un Estado de cambiar su modelo económico resulta una causa suficiente para llevar a cabo una nacionalización ${ }^{61}$. En lo relativo a la exigencia de un procedimiento contradictorio, difícilmente podrá ser utilizado en las nacionalizaciones que, por definición, se llevan a cabo a través de leyes que afectan a la totalidad de la economía de un país ${ }^{62}$. Finalmente, se debe analizar la exigencia de indemnización, el motivo más utilizado a la hora de fundamentar la no conformidad con el orden público en los casos de validez extraterritorial de nacionalizaciones ${ }^{63}$.

79. La jurisprudencia del Tribunal Supremo español, aunque también se basa en las garantías constitucionales relativas a la expropiación forzosa, se centra fundamentalmente en el requisito de la indemnización ${ }^{64}$. La falta de tal compensación sirve de argumento para fundamentar la contrariedad de

israelí, de 30 de junio de 1971, «caso Bacardí»; Tribunal Supremo italiano, de 5 de octubre de 1959, «caso Archimedes»; Tribunal Supremo austriaco, de 3 de febrero de 1954, «caso Danuvia»; Tribunal Supremo austriaco, 14 de enero de 1953 y 14 de septiembre de 1955, «caso Carborundum»; vid. A. QUIÑONES ESCAMEZ, op.cit., nota 44, pp. 239-247.

${ }^{59}$ Este requisito ha sido alegado, especialmente, en las nacionalizaciones de los países del tercer mundo, a los cuales se les acusa de nacionalizar sociedades que sólo afectan a los intereses de las personas con una determinada nacionalidad, los nacionales de los respectivos países colonizadores. Por el contrario, se ha defendido dichas nacionalizaciones como instrumentos para restablecer una igualdad antes inexistente. De manera que, con tales actos, se trata de forma diferente situaciones que eran desiguales, como era la situación privilegiada de la que gozaban los países colonizadores, respecto de otros países en dicha ex colonia. En este sentido, se pronunció el Tribunal de Apelación de Bremen, en relación con la nacionalización de propiedades holandesas, entre ellas plantaciones de tabaco, por parte de Indonesia, vid. A. K. BOYE, op. cit., nota 52, pp. 107-113; M. DOMKE,"Indonesian nationalization measures before foreign courts", AJIL, Vol. 54, n², 1960, pp. 305-323, en especial pp.315-316, pp. 322-323; ID., loc. cit., nota 44, pp. 600-603; T. HEFTI, op. cit., nota 44, pp. 229-230; A. SADEK EL-KOCHERI, loc. cit., nota 44, p. 260.

${ }^{60} \mathrm{Vid}$. A.-L. CAlVo CARAVACA/ J. CARRASCOSA GONZÁLEZ, op. cit., nota 29, pp. 1225-1226.

${ }^{61}$ En este sentido, la propia ley nacionalizadora cubana, la Ley 890, justificaba la nacionalización por causa de interés público, social y nacional (art.6). Alegar la ausencia de interés público por parte de los perjudicados, en pocas ocasiones, podrá tener éxito, a menos que la nacionalización hubiera ido mucho más allá de cualquier límite razonable, Vid. M. DOMKE, loc. cit., nota 44, pp. 590-591; т. HEFTI, op. cit., nota 44, p. 228.

${ }^{62}$ En el caso de las nacionalizaciones cubanas, los procedimientos fueron muy breves, sin apenas formalidad alguna, basándose en una mera notificación a los perjudicados. Vid. c. GARREAU DE LOUBRESSE, loc. cit., nota 45, p. 224.

${ }^{63} \mathrm{Vid}$. А. K. BOYE, op. cit., nota 52; p.91; M. DOMKE, loc. cit., nota 44, p. 603; т. HEFTI , op. cit., nota 44, p. 227.

${ }^{64}$ En la Sentencia de 25 de septiembre de 1992, el TS fijaba tres requisitos para reconocer en España efectos a una nacionalización extranjera: a) la presencia de causas reales concretas; b) la existencia de un expediente contradictorio previo y; c) la verificación de una compensación económica. Estas tres condiciones coinciden con las garantías de la propiedad privada frente al poder expropiatorio recogidas en el art. 33.3 CE. Sin embargo, la utilización de estas tres garantías como contenido del orden público internacional español a la hora de otorgar eficacia extraterritorial a las nacionalizaciones extranjeras ha sido duramente criticada por la doctrina. Vid. F. J. GARCIMARTín Alférez, loc. cit., nota 55, pp.883-884; P. JIMÉNEZ BlANCO, loc. cit., nota 55, p. 382. Dichas garantías están pensadas para procedimientos de expropiación, llevados a cabo mediante la aplicación de la Ley de 16 de diciembre de 1954 de expropiación forzosa pero no para otorgar eficacia en España a nacionalizaciones extranjeras. Así, en cuanto a la primera de ellas - la presencia de causas reales y concretas-, y como se dijo anteriormente, es causa más 
tal nacionalización con el orden público ${ }^{65}$. Por tanto, cabe afirmar que, en esta materia, la vulneración del orden público internacional con vistas a rechazar o aceptar efectos a una medida de nacionalización gira en torno a la existencia de indemnización ${ }^{66}$.

80. Aunque no es una cuestión pacífica, se ha llegado a defender por un sector de la doctrina que la obligación de pago de una indemnización como condición de validez de la nacionalización constituye un principio general de derecho positivo dentro del Derecho internacional público ${ }^{67}$. Si bien, esta posición no se puede fundamentar en la Declaración Universal de Derechos Humanos de 1948, en tanto que en su art.17, sobre el derecho de propiedad, no establece tal garantía, lo cierto es que la práctica internacional de los Estados impone la existencia de tal obligación: las nacionalizaciones deben ir acompañadas de una indemnización razonable en el tiempo, efectiva y adecuada. El argumento más utilizado para fundamentar dicha práctica internacional de los Estados es que incluso los países de corte comunista han concluido Convenios internacionales con tal previsión de compensación como consecuencia de nacionalizaciones, y no sólo han elaborado dichos Convenios con Estados occidentales, sino incluso entre los propios países del mismo sesgo ideológico ${ }^{68}$.

81. En el caso de Cuba, la indemnización estaba prevista en la Ley 890 de 13 de octubre de 1960, en relación con la Ley 956 de 24 de agosto de 1961-, si bien es cierto no se llegó a materializar ${ }^{69}$. Con el paso del tiempo, el Estado cubano ha intentado solucionar este escollo recurriendo a distintos mecanismos, como la celebración de convenios bilaterales con aquellos Estados cuyos nacionales quedaron afectados por la nacionalización sin mediar compensación. Tal es el caso del Convenio celebrado entre España y Cuba sobre indemnización por los bienes españoles afectados por las leyes, disposiciones y medidas dictadas por el Gobierno de la República de Cuba a partir del 1 de enero de 1959, firmado en La Habana el 16 de noviembre de $1986^{70}$. El citado Convenio bilateral es un acuerdo de compensación global (lump sum agreement), esto es, un acuerdo mediante el cual, el Estado nacionalizador y el Estado cuya nacionalidad ostentan los perjudicados, fijan una suma global como indemnización fijando unos plazos para su pago. A cambio, el Estado cuyos nacionales sufrieron la nacionalización renuncia a

que suficiente querer modificar el modelo económico de un país, además también se ha argumentado que, en este caso, se está exigiendo más incluso que en un procedimiento expropiatorio, donde se debe especificar no la causa de la expropiación en sí, sino el fin al cual se va a dedicar el bien expropiado. En lo relativo al requisito del procedimiento, se debe decir que, incluso en casos de urgencia, este requisito no es exigible en una expropiación. Del requisito constitucional de la indemnización, el más importante, y en el que se centra la sentencia del Tribunal Supremo comentada, se desprende que ésta debe existir en todo caso. Ahora bien, aunque esta exigencia se refiera a la expropiación, el Tribunal Constitucional admite que dicha compensación no tiene porqué ser siempre previa, si bien, sí que debe existir un razonable equilibrio entre daño expropiatorio y su reparación, esto es, la indemnización debe corresponder con el valor económico del bien o derecho expropiado (Sentencia del Tribunal Constitucional, de 19 de diciembre de 1986). En definitiva, el contenido del orden público internacional en esta materia, conformado principalmente por lo establecido en el art. 33.3 CE, debiera adecuarse a la propia naturaleza y características de las nacionalizaciones, especialmente, en relación con los rasgos definidores de la indemnización, por ser ésta la exigencia más decisiva. Vid. A. QUIÑONES ESCAMEZ, op. cit., nota 44, pp. 252-253. En relación con la indemnización, A. K. BOYE, entiende que no se puede asimilar la nacionalización a la expropiación por causa de utilidad pública (op. cit., nota 52, pp. 91-92, p. 97).

${ }^{65}$ Vid. STS (Sala de lo Civil), de 30 de diciembre de 2010, FJ $10^{\circ}$.

${ }^{66} \mathrm{La}$ ausencia de indemnización ha sido y es el argumento generalmente utilizado para alegar el incumplimiento del orden público, y con él, denegar la eficacia extraterritorial de las nacionalizaciones, vid. I. GUARDANS I CAMBÓ, op. cit., nota 49, p. 240; A. QUIÑONES ESCAMEZ, op. cit., nota 44, p. 253; M. SAVATIER, loc. cit., nota 44, pp. 55-57.

${ }^{67}$ Sobre la controversia en torno a la existencia de tal obligación en el Derecho internacional público, vid. A. K. BOYE, op. cit., nota 52, pp. 92-93; т. HEFTI, op. cit., nota 44, pp. 230-231, pp. 250-251; A. REMIRO BROTONS, Derecho internacional público. Principios fundamentales, $1^{a}$ ed., Madrid, 1987, pp. 307-309; M. SAVATIER, loc. cit., nota 44, pp. 52-53; I. SEIDL-HOHENVELDERN, loc. cit., nota 49, p. 127.

${ }^{68}$ Vid. M. DOMKE, loc. cit., nota 44, pp. 603 -604; т. HeFTI, op. cit., nota 44, pp. 147-152.

${ }^{69} \mathrm{M}$. DOMKE afirma que la promesa de compensación futura en la ley nacionalizadora no es suficiente para cumplir con esta exigencia (loc. cit., nota 27, pp. 604-607). Sin embargo, también se ha defendido que dicha promesa no es vulneradora del orden público, en este sentido, se ha propuesto la suspensión de los efectos extraterritoriales de la nacionalización en tanto no se llegue a un acuerdo en torno a la indemnización, pero no la denegación inmediata de los mismos, vid. A. SADEK EL-KOCHERI, loc. cit., nota 44, pp. 261-262 y p. 274.

${ }^{70}$ BOE núm.67, de 18 de marzo de 1988. 
presentar cualquier reclamación o reivindicación a tal efecto ${ }^{71}$. En el marco del mencionado texto convencional, el Estado cubano sólo se obliga a indemnizar a las personas físicas o jurídicas de nacionalidad española (arts. 1 y 3$)^{72}$. El citado instrumento internacional no hace más que recoger la obligación impuesta a los Estados por el Derecho internacional público, consistente en la exigencia de indemnización para los perjudicados extranjeros perjudicados por un acto de nacionalización ${ }^{73}$.

82. Por tanto, para determinar si el Estado cubano ha cumplido o no, con su obligación de pago de indemnización habría que distinguir dos supuestos según la nacionalidad de los perjudicados por el acto de nacionalización. Así, si los afectados son españoles, resultaría de aplicación el Convenio hispano-cubano, quedando intacto el orden público internacional español. En el caso de que los perjudicados por el acto de nacionalización fueran cubanos, tampoco quedaría afectado el orden público internacional español. El Estado cubano es libre de indemnizar o no a sus nacionales, tal y como se deriva del principio de soberanía económica de cada Estado, ya que ni la exigencia de una indemnización es un derecho fundamental, ni la nacionalización afecta a la libertad de mercado defendida por nuestra Constitución ${ }^{74}$. A igual conclusión se debiera llegar si los afectados por la nacionalización ostentaran la nacionalidad de un tercer Estado.

83. Sin embargo, no es ésta la posición mantenida por el Tribunal Supremo. Para el alto tribunal, la nacionalización llevada a cabo en Cuba no afecta a la libertad de mercado (art. $38 \mathrm{CE}$ ), pero sí que incumple el requisito de la indemnización (art.33.3), el cual, al igual que el primero, no necesitan ser derechos fundamentales (Sección 1 ${ }^{\mathrm{a}}$, Capítulo II, Título I CE) para formar parte del orden público internacional español ${ }^{75}$. Para el Tribunal Supremo, el orden público internacional español contiene la necesidad de que exista una compensación cuando por razones de interés general se pierde la propiedad de un bien, es una consecuencia directa del derecho de propiedad privada, que aunque no es un derecho fundamental, sí se considera uno de los principios básicos de nuestro ordenamiento jurídico, y valor esencial de la sociedad a la que éste sirve ${ }^{76}$.

84. Siguiendo estos planteamientos, tanto si los perjudicados eran cubanos, como si eran españoles, parece claro que el Tribunal Supremo acierta cuando se pronuncia sobre este punto. La nacionalización es contraria al orden público internacional español debido a la falta de indemnización a favor de los perjudicados. Sin embargo, para verificar la denegación o no de la eficacia extraterritorial de la nacionalización cubana, queda por analizar si, efectivamente, el caso está suficientemente vinculado con España como para dañar dicho orden público.

85. Partiendo de la inexistencia de normas que concreten dicho vínculo, se ha entendido como conexión suficiente la situación del bien nacionalizado en el Estado donde se pretende su eficacia extraterritorial ${ }^{77}$. Este es el criterio utilizado por el Tribunal Supremo español en los dos casos que hasta

\footnotetext{
${ }^{71}$ Vid. T. HEFTI, op. cit., nota 44, pp. 136-139; s. PETREN, loc. cit., nota 44, p.555.

${ }^{72}$ Sobre el diferente tratamiento entre nacionales y no nacionales del Estado nacionalizador, vid. T. HEFTI, op. cit., nota 44, pp. 139-142, 251-252.

${ }^{73}$ Vid. M. DOMKE, loc. cit., nota 44, pp. 609-610; s. PETREN, loc. cit., nota 44, p. 556. Sin embargo, otros autores entienden que estos convenios son la manifestación de otra nueva práctica internacional, vid. T. HEFTI, op. cit., nota 44, pp. 139-142.

${ }^{74}$ Vid. F. J. GARCIMARTín ALFÉREZ, loc. cit., nota 55, pp. 885-886.

${ }^{75}$ Éste está formado por principios, los cuales, pueden extraerse tanto de la Constitución, como de otros cuerpos legales, vid. A.-L. CAlvo CARAVACA/ J. CARRASCOSA GONZÁlez, op. cit., nota 1, pp. 327-357.

${ }^{76}$ No sólo es un pilar fundamental del ordenamiento jurídico español, sino también de los ordenamientos jurídicos europeos, prueba de ello es que es un derecho reconocido, en una forma muy similar a la recogida en la CE, por el art. 1 (Protocolo núm. 1) del Convenio Europeo para la protección de los Derecho Humanos y de las Libertades Fundamentales, Roma, 4 de noviembre de 1950, (BOE núm. 108, de 6 de mayo de 1999) y la interpretación que de éste ha dado el Tribunal Europeo de Derechos Humanos y por el art. 17 de la Carta de los Derechos fundamentales de la Unión Europea (DOUE C 83/02, 30 de marzo de 2010), incluida en el Tratado de Lisboa por referencia del art. 6 del Tratado de la Unión Europea, (DOUE C 83/01, 30 de marzo de 2010).

77 Vid. I. SEIDL-HOHENVELDERN, loc. cit., nota 49, pp. 126-127.
} 
ahora se le han planteado. En ambos, establece dicha conexión con la localización de la marca, situada en España en virtud de su inscripción en el Registro español de Propiedad Industrial ${ }^{78}$. Ahora bien, la intensidad de dicho vínculo y la rigurosidad con la que se considere el incumplimiento del orden público tienen que ir necesariamente unidas ${ }^{79}$.

86. Si aplicamos todo lo hasta aquí expuesto al asunto Central Santa Lucía contra Meliá Hoteles, observamos que: a) los perjudicados por el acto de nacionalización en Cuba eran de nacionalidad cubana, devenidos posteriormente estadounidenses; b) en ningún momento, medió compensación por el acto de nacionalización; c) la pretensión del demandante no tiene por objeto reivindicar la propiedad del bien nacionalizado, dato este que difiere de la jurisprudencia existente sobre esta materia en España.

87. Por tanto, y una vez planteado el debate jurídico en sus justos términos, los tribunales españoles deberán valorar si, en este caso concreto, procede o no aplicar el orden público internacional de proximidad. Teniendo en cuenta la jurisprudencia del Tribunal Supremo español, el acto de nacionalización llevado a cabo en Cuba con independencia de la nacionalidad de los perjudicados vulnera el orden público internacional español. Ahora bien, en los dos casos planteados ante el Tribunal Supremo, existía una vinculación con España y, lo más importante, la cuestión principal versaba sobre la propiedad del bien nacionalizado.

88. Si bien es cierto que en el asunto Central Santa Lucía contra Meliá Hoteles, el bien nacionalizado no está situado en España, no lo es menos que está siendo explotado por una empresa con domicilio en nuestro país. A ello hay que unir que, a diferencia de los dos casos planteados ante el Tribunal Supremo español, la parte actora en ningún aso reivindica la titularidad dominical del bien inmueble que en su día fue objeto de nacionalización. Circunstancias todas ellas, que deberán ser tenidas en cuenta a la hora de resolver la cuestión previa, que afecta a la acción principal relativa al enriquecimiento injusto.

\section{Conclusiones}

89. Cuando los Estados recurren al poder legislativo para resolver cuestiones de política exterior, no solo rompen las reglas del juego democrático, sino que al mismo tiempo hacen tambalear las relaciones internacionales. Un claro ejemplo de ello es Título III de la Ley Helms-Burton. La activación del mismo por la Administración Trump en abril de 2019, trata de imponer al resto de los países del mundo, el embargo de EEUU a Cuba, exigiendo a las empresas extranjeras que comercien con dicho Estado una tasa de inversión.

90. Para defenderse de los efectos extraterritoriales de una normativa de tal naturaleza, la UE, al igual que otros Estados, han adoptado "normas antídoto", tendentes a neutralizar los efectos que pudieran derivarse de las futuras demandas que se pudieran ejercitar contra empresas vinculadas con intereses comunitarios. Aunque aún es pronto para valorar las consecuencias de esta guerra transoceánica de Derecho Internacional Privado, resulta decepcionante presenciar la utilización de unas normas cuyo principal objetivo es fomentar las relaciones privadas internacionales y no, las relaciones entre Estados.

91. Con este telón de fondo, se plantea ante los tribunales españoles el asunto Central Santa Lucía contra Meliá Hoteles. En ningún momento se alude a la aplicación de la Ley Helms-Burton, razón por la que el "Estatuto de Bloqueo UE" queda neutralizado, si bien es cierto, dicho asunto obliga a los tribunales españoles a pronunciarse sobre el acto de nacionalización que tuvo lugar en Cuba a partir del año 1959.

\footnotetext{
${ }^{78}$ En el asunto "Havana Club", sin embargo, existían dudas más que razonables para considerar que el caso estuviera suficientemente vinculado con España como para activar el orden público internacional español. Vid. A. HERNÁNDEZ RODRíGUEZ/ C. MACHO GÓMEZ, loc. cit., nota 56, pp. 174-175.

79 Vid. P. JIMÉNEZ BLANCO, loc. cit., nota 55, pp. 382-383; I. SEIDL-HOHENVELDERN, loc. cit., nota 49, p. 128.
} 
92. Tras una incorrecta e inapropiada aplicación de la inmunidad de jurisdicción por parte del Juzgado de Primera Instancia de las Islas Baleares, y una vez reconducido el debate de dicho asunto en sus justos términos por la Audiencia Provincial, resta resolver la cuestión previa planteada, centrada en la eficacia internacional de las nacionalizaciones.

93. Teniendo en cuenta la jurisprudencia del Tribunal Supremo existente sobre esta materia, no cabe ninguna duda de que el acto en virtud del cual fueron expropiados los terreros actualmente explotados económicamente por Meliá Hoteles, vulnera el orden público internacional español.

94. Si se aplicara el orden público internacional de proximidad en el asunto Central Santa Lucía contra Meliá Hoteles, tal y como propone la doctrina en tales casos, ello conduciría a primera vista a reconocer eficacia al acto de nacionalización, principalmente porque el bien nacionalizado está situado en Cuba, y no existe ninguna otra vinculación con nuestro país. No obstante, debería tenerse en cuenta que, en este asunto, a diferencia de otros planteados ante los tribunales no solo españoles sino también extranjeros relativos a los actos de nacionalización, la cuestión principal no versa sobre la reivindicación de la propiedad del bien nacionalizado sino sobre el enriquecimiento injustificado. Dato este que tal vez, pudiera dar un giro inesperado a la resolución de este apasionante asunto... 